\title{
Dispersion in macroeconomic volatility between the core and periphery of the international trade network
}

\author{
Anindya S. Chakrabarti * \\ Economics area, Indian Institute of Management \\ Vastrapur, Ahmedabad-380015, India
}

August 25, 2015

\begin{abstract}
At the country level, macroeconomic volatility tends to correlate with trade openness although the direction of correlation is not stable across samples. Here I consider trade networks as sum of all pairwise trade linkages to emphasize that different linkages contribute differently to the transmission or mitigation of shocks, and show that across the network volatility is inversely related to centrality, a summary measure of strength of the linkages specific to a country. I study a multi-country, multi-sector trade model subject to idiosyncratic productivity and liquidity shocks, and characterize volatility as an explicit function of centrality, diversification and the Herfindahl of the trade network in equilibrium. With sufficient skewness in trade linkages across countries, similar shocks generate different levels of repercussions across the network. The conventional effect of diversification holds true that countries with better diversified portfolio fluctuate less compared. Centrality directly contributes to better aggregation of shocks. Combined effect of these two channels dominates the opposite effect that a more central country is also more exposed to shocks. The model calibrated to the E.U. generates and closely replicates the negative relationship between centrality and volatility. The theoretical model is then extended to capture stochasticity and sparsity in the trade networks.
\end{abstract}

*Email address: anindya@bu.edu

I thank Alisdair McKay and Adam Zawadowski for advising me on this work. I also thank Alireza TahbazSalehi, Miklos Koren, Adam Guren, Simon Gilchrist and Robert King for many helpful comments. Finally, I have benefited from discussions with Samuel Bazzi, Sambuddha Ghosh, Ei Yang, Felipe Cordova, Carlos Ramos, Arnab Chatterjee, Sitabhra Sinha and Bikas K. Chakrabarti. A previous version of this paper was circulated as 'Globalization of volatility'. 
Keywords: Macroeconomic volatility, Centrality measure, International trade, Markov chain.

JEL classification: E32, E41, F44, F62.

\section{Introduction}

How does the number and identity of trading partners affect a country's macroeconomic volatility? The current global economy is reminiscent of a massive complex input-output system comprising an intertwined set of countries producing goods and services, each importing and exporting inputs and outputs to each other forming the network of trade. In this paper, I argue that the structure of the trade network as a whole is an important factor affecting country-level volatility in the sense that the latter is a complex outcome of interaction between how a country dissipates idiosyncratic shocks to its neighbors and how the spill-over effects from other countries propagated through the network affect the domestic volatility. I show that the dispersion in trade linkages in the network contributes to the dispersion of cross-country volatility.

To understand the relationship between centrality of the countries and their corresponding macroeconomic volatility, I adopt a network theoretic point of view which emphasizes the nature of trade linkages of the whole set of countries simultaneously rather than considering bilateral linkages between pairs of countries in isolation from the rest of the world. Thus as opposed to sheer volumes of trade, we show that what really matters for volatility is who are the neighbors in the trade network, who are the neighbors' neighbors and so on. The fact that asymmetry in linkages has implications for volatility was put forward by Acemoglu et al. [2012]. They argue in the context of an input-output model that in an economy comprising many sectors with sufficient dispersion in intersectoral linkages, idiosyncratic shocks of different sectors explain a substantial portion of aggregate volatility. Thus in a sufficiently granular economy, the 'diversification' argument fails for the aggregate volatility in the sense that idiosyncratic shocks do not cancel each other. An immediate precursor of this idea can be found in the 'granular hypothesis' forwarded by Gabaix [2011] who shows that if an economy is made of firms with sufficient dispersion in size, then again idiosyncratic shocks do have an effect on aggregate volatility. I take a step further and explain why different nodes in a granular economy might show different levels of volatility in the first place, in response to similar external shocks. More precisely, I construct a theoretical model to show that the skewness of the linkages in the trade network explains the differences in cross-country volatility in a world with ex-ante symmetric islands ${ }^{1}$ subjected to symmetric, idiosyncratic

\footnotetext{
${ }^{1}$ In the rest of the paper, I will use the words island and country interchangeably.
} 
shocks and an exogenous and fixed trade network.

From the perspective of a single country embedded in a trade network, the network approach allows me to study the diffusion of domestic idiosyncratic shocks across the neighbors and aggregation of foreign shocks. This aspect of the model is close to the traffic jam theory of recession proposed by La'o [2014]. Any imbalance in one country sends ripples of economic activities through the linkages to its neighbors in the trade network. However, as opposed to cyclic networks considered in the traffic jam model, I allow any arbitrarily complicated network. More precisely, I construct a model of multiple islands connected to each other forming a flow network of a primitive asset that is payed to settle current account surpluses or deficits. The theoretical model thus endogenously generates a weighted and directed flow network defined over a set of countries mimicking the nominal trade flow network. This feature of the model provides a micro-foundation to the cross-sectional primitive asset holding network proposed by Jackson et al. [2014] who analyze propagation of shocks through the linkages of a network with arbitrary structure. The analysis of individual country's volatility is based on a canonical dynamic neo-Keynesian model with liquidity constrained agents (as in Midrigan and Philippon [2011]) and sticky prices (Calvo [1983]).

In the model, I consider a set of islands endowed with differentiated tradable goods and produce non-tradable goods. They also hold a non-consumable liquid asset, the supply of which is fixed from outside. For simplicity, let us call it money. As an example, imagine that island $A$ gets an endowment of apples, island $B$ gets an endowment of bananas and the endowment processes are i.i.d. across islands. Each island is inhabited by unit mass of households who supplies labor and capital to produce housing service which is non-tradable. The preferences of households are defined over a bundle of tradables and the non-tradable goods. Thus products differentiated according to their origin along with preferences defined over them provide incentives to trade. Finally, the households are liquidity constrained, the total amount of liquidity being the amount of liquid asset the households have and the revenue generated from selling their products (Apples and Bananas) in the international market. Now, if island $A$ runs a current account surplus by exporting more than it imports, then there will be an inflow of the liquid asset to maintain zero balance of payment. This relaxes the liquidity constraint for island $A$ and tightens the same for island $B$. Assuming prices are sticky in the non-tradable sector i.e. housing, demand will increase in the island $A$ and decrease in island $B$. Thus labor employment, wage rate, rental rate, output will show movements in opposite directions.

I extend this basic framework in several steps. First, the whole setting is made dynamic along with capital formation in the domestic economy allowing the usual consumptionsmoothing mechanism to work. Second, the model incorporates $N \geq 2$ islands allowing 
us to consider the effects of diversification of export portfolio. Third, the trade linkages are allowed to have arbitrary weights. Note that given the structure of the model, the trade network will be a function of the preference parameters i.e. the relative weights the countries assign to each others' tradables. I calibrate the trade network generated in equilibrium to the actual trade network. Thus the centralities of islands are pinned down from the relative weights of the trade linkages.

The role of the liquid asset in this model is to keep track of the nominal value of exports and imports as well as the nominal expenditure on domestic production. The nominal flow of traded goods across islands can be expressed in terms of this asset only as it is the numeraire of this world. Therefore, the trade flow network representing the nominal value of exports and imports across islands can be rewritten as a set of interdependent flow equations representing the law of motion of the liquid asset-holding. Any exogenous liquidity shock in the form of helicopter drop of money induces an imbalance in the relative asset holding and thus "waves" of adjustments takes place sending ripples of macroeconomics activities across islands. In real time such adjustments could be simultaneous, but such a framework is useful in analyzing how shocks propagate across countries based on the strength of the trade linkages and to potentially identify the islands which if shocked, induces a longer wave of adjustments through the network.

The main results are summarized as follows. First, the model endogenously generates an inverse relationship between centrality of countries in a trade network and their corresponding income volatility. This result hinges on a result that the more central islands accumulate a larger stock of liquid assets. Intuitively, a large fraction of fiscal stimulus in Greece will eventually end up in Germany as the latter is more central than the former (we are of course, ignoring other considerations like debt obligations here). To see why this is the case, let us assume that all of the countries are maintaining zero trade surplus and there is a non-degenerate distribution of liquidity across countries. By giving a stimulus, the receiving country suffers from an imbalance and when trading with its neighbors, redistributes a part of the additional money. The neighbors will also do the same in the next round of trading as now they have some excess money. Eventually more central countries, by virtue of being important suppliers to other countries, will receive the biggest share of the pie. Thus due to trade, countries experience liquidity inflow or outflow which entails fluctuations in liquidity available to be spent on domestic purpose (non-tradables like housing service for example). Given liquidity-constrained households and sticky prices, international trade will thus impact real consumption as prices cannot adjust quickly enough to nullify the effects of the changes in the stock of liquidity. Correspondingly, the effects are seen in all other country-specific aggregate real variables viz. wages, labor supply, rental rate, and capital 
holding. Since central islands hold larger stocks of liquidity, idiosyncratic and identically distributed liquidity shocks will induce smaller percentage changes the growth rates of the stock and consequently induce lower macroeconomic volatility. Thus the mechanism leads to asymmetric responses across the countries due to asymmetries in the trade network itself, even though all countries can have similar conditions in the domestic labor market or the commodity market.

Second, the local effects of diversification still holds true. In the earlier case, we talked about centrality as a global measure of importance in the trade network and showed its equivalence in terms of asset holding. This basically describes the endogenous robustness of the islands in response to shocks. A complementary effect is present that an island with well diversified export portfolio also shows less volatility in income. The intuition is that with a well diversified portfolio, the islands are better equipped to reduce volatility by combining exogenous liquidity shocks coming from its neighbors. As will be shown below, the openness of an island also matters in the sense that a high exposure to shocks contributes positively to its volatility. But both of this effects are of second order importance compared to the first effect of centrality-liquidity relationship.

Third, a series of experiments on some specific regular networks gives important insights into the mechanism of shock propagation (Sec. 4). I show that with a symmetric trade network, all things unchanged, greater trade integration reduces macroeconomic volatility. Note that in a symmetric network, all islands are equally central. Thus the centrality channel does not work here. By having more trade linkages, countries can reduce volatility conditional on zero effects from centrality. This point requires clarifications. On the empirical ground, the literature provides ambiguous evidence on existence of a negative relationship between trade openness and volatility (see Sec. 8.1 for details). However, a less ambiguous point is that there actually is a negative relationship conditional on the portfolio being welldiversified (see for example Haddad et al. [2012] and Caselli et al. [2014]). Thus it is not the trade openness per se, that has a unidirectional effect on volatility. A disaggregated measure like the multilateral openness or in other words, the topology of the whole trade network, gives the correct description of the effects on volatility.

Note that with unequal degree of connectivity, both the centrality and diversification channels would work. If we consider a star-shaped network with one node forming the core and the rest being peripheral, then the later would show higher volatility than the former in response to similar liquidity shocks. Finally, I study how liquidity shock propagates from one island to another using a linear network. With a general network structure it is difficult to pin down the "wave" of adjustments as there can be multiple paths connecting any two islands. With a linear network (a chain of islands) we can circumvent that problem. In terms 
of impulse response functions it is seen that an unit liquidity shock to one end of the chain sends a ripple across the network as the receiving island holds a fraction of the additional money and transfers the rest to the downstream island due to trade which then becomes the new receiver. As expected, the further we move from the origin of the shock the lesser is its effect in terms of macroeconomic adjustments it causes.

\section{Empirical motivation}

There is substantial variation in macroeconomic volatility across countries (e.g. the most volatile country is more than four times more volatile than the least, in the sample). Stability associated with low volatility is of utmost importance for a multitude of economic issues ${ }^{2}$ making it a central concern from a policy-making perspective, in developing and developed countries alike. Fiscal, monetary and other related policies are often designed to insulate the economies from external disturbances or at least, to reduce the degree of fluctuations caused by such disturbances. Hence, understanding the key mechanisms generating or influencing macroeconomic volatility is important both from a theoretical and a practical point of view. To explain the cross-country differences in volatility, Giovanni and Levchenko [2012] argue that due to the interaction between trade and granularity in the economy, bigger economies show less volatility. On the other hand, Koren and Tenreyro [2007] show that volatility is also related to stages of development. Economies with higher per-capita income tend to fluctuate less due to modes of specialization in production. Here, I propose a complementary thesis that in a densely interconnected world, the relative weights of such connections has an important effect on country-specific volatility.

Skewed distribution of trade linkages poses an advantage and a disadvantage for smoothing out idiosyncratic shocks. Intuitively, a central country has more opportunities to diversify its exports reducing volatility whereas the same country is also more open to exogenous shocks which increases volatility. Fig. 1 shows the pattern in the actual data that a more central economy has a more stable income process indicating that centrality has an unambiguously negative effect on volatility. Fig. 1 presents a scatter plot of log volatility against $\log$ of eigenvector centrality for the European countries. Volatility is defined as the standard deviation of detrended (HP filtered) log per-capita GDP.

I use the recursive definition of centrality that one country's centrality is the weighted sum of all of its neighbors' centralities ${ }^{3}$. Thus intuitively, if the home country has a bigger trade

\footnotetext{
${ }^{2}$ For example, Ramey and Ramey [1995] finds effects of volatility on long-run growth, Barlevy [2004] links welfare loss to volatility and Prasad et al. [2007] finds important effects, both direct and indirect, on poverty.

${ }^{3}$ Google's PageRank algorithm is probably the most well known application of eigenvector centrality
} 


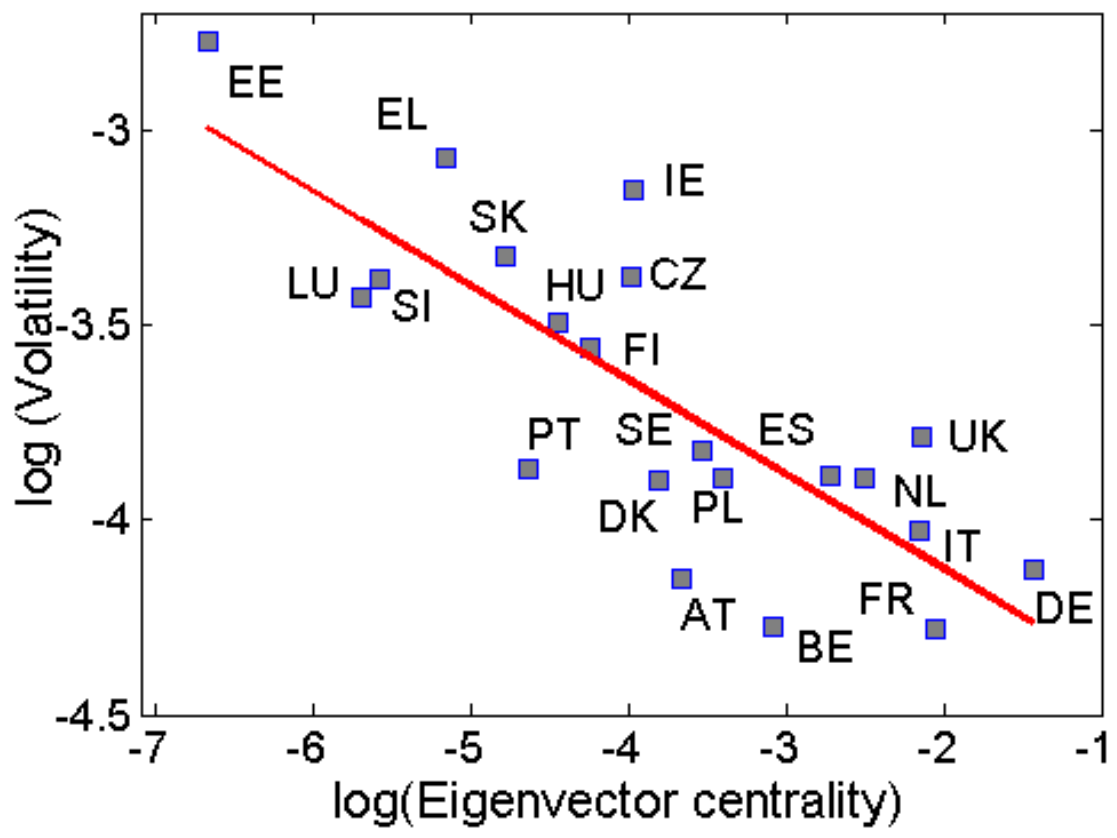

Figure 1: Log of volatility (standard deviation of detrended log per-capita output) of countries in Europe is plotted against log of eigenvector centrality of the countries in the intraEurope trade network. See text for definitions.

linkage with a more central country then centrality of the home country increases. Hence the home country should show more stability following the pattern in Fig. 1. This finding is consistent with and rationalizes the regularity found by Farshbaf [2012] that trading with more stable country induces stability on the home country. Empirically, it is seen that the effect of centrality on volatility is negative whereas the standard aggregative measures like trade openness are not very informative (Sec. 8.3). A similar finding is made also by Gray and Potter [2012] with a bigger set of countries. But in that case, it is not clear whether such a finding actually reflects a systematic relationship between the trade centrality and volatility or it arises due to differences in levels of development of financial markets or due to size effects. In general, the countries which are very central also happen to be very large and often with fairly developed financial markets thus making it difficult to disentangle their effects on volatility. To deal with that problem, I construct an instrument based on geographic centrality of the countries in the European Union and the trade centrality is instrumented by that variable. Trade centrality is still seen to have an effect on volatility (Sec. 8.3). Another way to motivate the impact of the cross-country linkages on the country-level volatility is that it implies non-trivial spill-over effects whereas country-specific explanations cannot generate such effects. 
We can formally define a network and the associated centrality index as follows.

Definition 1. A network is a pair $G \equiv(N, \mathcal{T}), \mathcal{T}$ is an $N \times N$ adjacency matrix defined on the set of nodes ${ }^{4} N$, where $\mathcal{T}_{i j}$ indicates the strength of relationship between nodes $i$ and $j$.

A network is directed if $T$ is asymmetric i.e. $\mathcal{T}_{i j} \neq \mathcal{T}_{j i} \forall\{i, j\}$, and is undirected otherwise.

Definition 2. Eigenvector centrality ${ }^{5}$ A of a network $(N, \mathcal{T})$ is the eigenvector associated with the largest eigenvalue of the adjacency matrix $T$.

The export-import table serves as the basis of construction of the adjacency matrix $T$ (see Appendix 8.2 for details) for plotting Fig. 1. See Table 9 for a list of names of countries with their abbreviations. Similarly, from the export-import table we can construct a measure of first-order centrality i.e. that takes into account of different countries presence in their respective trading partners' import baskets. Thus, if country $i$ supplies $\mathcal{T}_{i j} \geq 0$ fraction of its $j$-th partner's total import, then first-order centrality is defined as $\sum_{j} \mathcal{T}_{i j}$. Note that the usual idea of considering the number of trade partners (commonly termed as 'degree centrality' of a node) is of no help here as every country trades with every country albeit with different intensities.

We can go one step further and construct a measure taking into account not only direct neighbors but also neighbors' neighbors. Here, we first calculate the direct presence of the $i$-th country in its neighbors' import baskets as described above. Then we remove the $i$-th country from the network and compute its neighbors' first-order centrality in the reduced network $N /\{i\}$ and combine it with the $i$-th country's presence in the respective countries import baskets. Thus this is a measure of second-order centrality. As can be seen in both panels of Fig. 7, The relationship between both measures of centrality and degree of volatility is unambiguously negative.

\section{The model}

Consider a set of $N$ islands that trade with each other. Each island produces non-tradable and differentiated tradable goods ${ }^{6}$ and is populated by unit mass of households which consumes both a bundle of tradables and non-tradables and derives utility from leisure. The

\footnotetext{
${ }^{4}$ I also denote the cardinality of set $N$ by $N$.

${ }^{5}$ The centrality score of a node $i$ is defined as $a_{i}=\frac{1}{\lambda} \sum_{i \in G} \mathcal{T}_{i j} a_{j}$ where $\lambda$ is a constant. By rearranging and expressing it in terms of vector, we get $\mathcal{T} A=\lambda A$, which is evidently the solution of eigenvalues of matrix $\mathcal{T}$. It is also known as Bonacich centrality (Acemoglu et al. [2012]).

${ }^{6}$ The assumption that products are differentiated, at least from the consumers' perspective, according to their country of origin is called the Armington assumption (Armington [1969]).
} 
only means of payment by the household are provided by the central monetary authority. This nominal liquid asset imposes a constraint on the purchasing power of the households and hence creates the demand for the asset. As in Midrigan and Philippon [2011], this model can be interpreted as a large country with multiple states (for example, USA, China or India), or more appropriately, a monetary union with a collection of countries (for example, European Union) even though none of the results crucially depend on this assumption. We ignore country-to-country labor migration in the present formulation. Thus the production processes are spatially separated (Dumas [1992]).

\subsection{Sequence of events at time $t$}

Following the standard exposition of models with a cash-in advance constraint, we assume that each household has two members, one shopper and one producer. At any generic timepoint $t$, the following sequence of events take place. At the beginning of the period, each island gets stochastic endowments of a country-specific tradable good and a non-consumable, tradable nominal liquid asset. The implicit idea is that the money market opens first and the central monetary authority engages in open market operations providing the households with a stochastic endowment of nominal assets. As far as the tradables are concerned, we assume that islands have comparative advantages in production of an unique commodity and hence, each country specializes in only one tradable good. But preferences are defined over all tradables which provides incentives to trade. At the next step, the international market opens to carry out trade between islands. The pre-existing stock of asset and the new additional assets along with the nominally evaluated tradables is the aggregate liquidity available to the households, which they decide how to split between consumption of tradables and non-tradables (Clower [1967]). The shopper trades in a perfectly competitive international market. This leads to an inflow or outflow of liquidity depending on whether the she runs a trade surplus or deficit. The balance of payment equation holds i.e. trade surplus equals net asset flow. Then she goes to the domestic market to purchase non-tradable goods. At this point, the producer wakes up and goes to the domestic labor market and earns wage and rental income after providing labor and capital (as the households are also the capital-owners). The intermediate goods producers combine labor and capital to produce

a continuum of intermediate goods which are, in turn, bundled into the final good. Thus the households also earn a net profit from producing intermediate goods which is accounted for in the flow budget constraint.

Fig. 2 provides a visual description of the sequence of events. An assumption we make which simplifies the model a lot, is that tradables are consumed in the same period ei- 


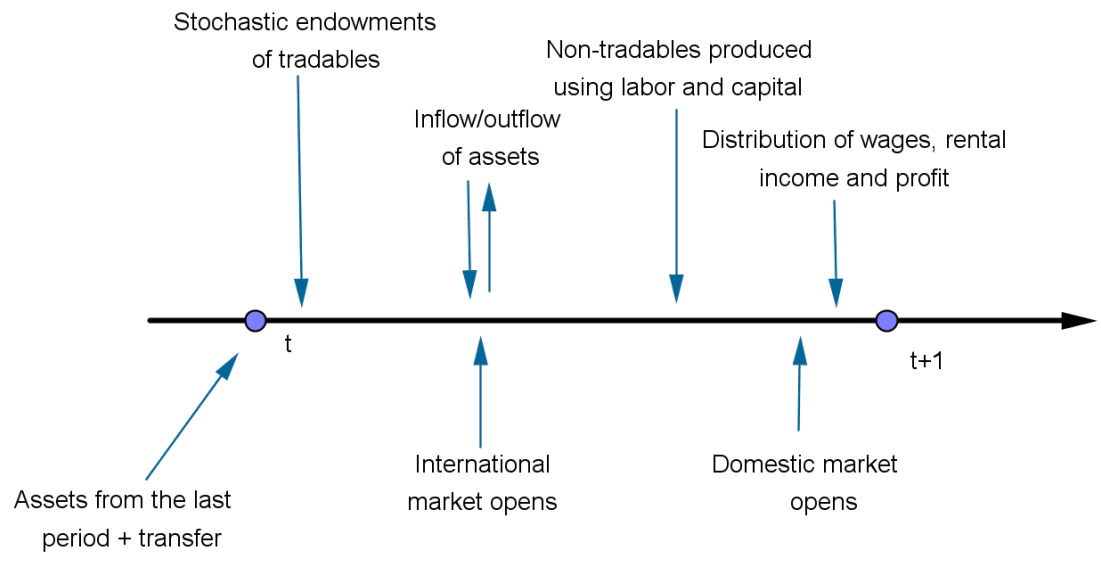

Figure 2: sequence of events at any generic time point $t$.

ther because they are perishable or used as intermediates to produce something else that is consumed immediately. One can think of agricultural goods, fisheries, hotel and transport services or mining products like natural gas, coal, oil etc. as examples of tradables. On the other hand, capital accumulation is possible only with non-tradable goods and the capital is fixed, island-specific capital. For example, construction, finance, real estate service or public services (building schools, hospitals or roads) are non-traded due to their very nature. In short, one can think of commodities like 'apples' and 'oranges' being the tradables and 'housing' being non-tradable. An alternative interpretation is that the tradables are intermediates that are bundled in each country and then consumed (see Sec. 7).

\subsection{Household behavior in the $i$-th island}

Let us define an utility function of the a representative consumer of the $i$-th island ${ }^{7}$,

$$
U_{i}=\sum_{t=0}^{\infty} \beta^{t} E_{0}\left(\alpha_{i} v_{1}\left(C_{i}^{F}(t)\right)+\left(1-\alpha_{i}\right) v_{2}\left(C_{i}(t)\right)-\bar{B}_{i} L_{i}(t)\right)
$$

\footnotetext{
${ }^{7}$ Islands/countries are nodes of the trade network.
} 
where $C_{i}^{F}$ is the composite consumption good that is bought from the international market. $C_{i}$ denotes consumption of the domestically produced goods and finally, $L_{i}$ denotes labor provided by the household ${ }^{8}$. There are two constraints that the households face. First, there is a liquidity constraint (cash-in advance constraint) on the household. The aggregate stock of liquidity consists of pre-existing stock of liquidity $\left(a_{i}(t-1)\right)$, additional endowment of liquidity in form of transfer payment $\left(\Delta a_{i}^{e x o}(t)\right)$ and appropriately priced tradables, which the household spends on domestic and foreign consumption $\left(C_{i}(t)\right.$ and $C_{i j}^{F}(t) \forall j \in N$ respectively) goods. Finally, there is a flow budget constraint that keeps track of trade-off between present versus future consumption (in the form of capital $K_{i}(t+1)$ and real balance). The relevant constraints are as follows:

$$
\begin{aligned}
P_{i}(t) C_{i}(t)+\sum_{j}^{N} P_{j}^{F}(t) C_{i j}^{F}(t) & =a_{i}(t-1)+P_{i}^{F}(t) Y_{i}^{F}(t)+\Delta a_{i}^{e x o}(t), \\
K_{i}(t+1)+\frac{a_{i}(t)}{P_{i}(t)} & =w_{i} L_{i}(t)+r_{i} K_{i}(t)+(1-\delta) K_{i}(t)+\xi_{i}(t) .
\end{aligned}
$$

There is nominal friction in pricing and I will introduce it by considering a sticky price model in a monopolistically competitive production sector for the non-traded good (i.e. 'Housing'). Given the market structure, there will be a profit from owning the firms that will accrue to the households. The profit $\xi_{i}(t)$ has been accounted for in the flow budget constraint. Note that capital accumulation is done only through domestic, non-traded good. This assumption simplifies the analysis considerably.

\subsection{Supply side of the $i$-th island}

There are two production processes in each of the islands; one for the tradables and the other for non-tradables.

\subsubsection{Endowments of tradables}

The process for tradables are simple viz. we assume an exogenous stochastic endowment process for the tradables. The endowment processes are assumed to be symmetric across the islands. Thus they do not contribute to cross-country variation in income. The nontradables have a more complicated production process and can be used to produce capital stock or used as a consumption good.

\footnotetext{
${ }^{8}$ The parameter, $\bar{B}_{i}=\left(1-\alpha_{i}\right) B$ so that the elasticity between non-tradables and labor remains unchanged even if the relative weight assigned to tradables and non-tradables change across islands. Thus the domestic consumption-labor trade-off remains independent of the trade pattern.
} 
We follow a sticky-price model (à la Calvo [1983]) of the supply side of the non-tradables where there is a perfectly competitive final goods sector and a monopolistically competitive intermediate goods sector. The final goods sector bundles the intermediate goods following a standard technology with Dixit-Stiglitz specification. Intermediate goods are produced with capital and labor supplied by the households. The households are also the firm-owners and with monopolistic competition, the profits will accrue to them.

\subsubsection{Non-tradable good: final goods firms in the $i$-th island}

We assume that there is a unit continuum of firms (indexed by $\kappa \in[0,1]$ ) supplying intermediate goods to the final goods producing firms in each island. Also each of the intermediate goods are different from others making the intermediates imperfectly substitutable. There is set of competitive, final goods producing firms that uses a bundling technology to bundle the intermediate goods into a final good. The technology is given by the following constant elasticity of substitution bundling function:

$$
Y_{i t}=\left[\int_{0}^{1} Y_{i t}(\kappa)^{\frac{\psi-1}{\psi}} d \kappa\right]^{\frac{\psi}{\psi-1}},
$$

with $\psi>1$. A profit maximizing final goods producing firm will choose to maximize

$$
\pi_{i t}=P_{i t} Y_{i t}-\int_{0}^{1} P_{i t}(\kappa) Y_{i t}(\kappa) d \kappa,
$$

subject to the above bundling technology. As the final goods market is competitive, this profit has to be zero. By solving the problem (see Appendix 8.8.4 for a detailed derivation of the price index), the aggregate price index of the final good, is given by

$$
P_{i t}=\left[\int_{0}^{1} P_{i t}(\kappa)^{\psi-1} d \kappa\right]^{\psi-1} .
$$

\subsubsection{Non-tradables: intermediate goods producing firms}

The production function of the intermediate firm producing $\kappa$-th variety is given by the usual functional form

$$
Y_{i t}(\kappa)=\lambda_{t}\left(K_{i t}(\kappa)\right)^{\theta}\left(L_{i t}(\kappa)\right)^{1-\theta}
$$

where all firms receive the same productivity shock, $\lambda_{t}$. We assume that each firm has a constant probability $\rho$ of keeping the price unchanged and $(1-\rho)$ of optimally resetting the price. It can be shown that the firms that will reset the price would choose the same new price irrespective of their history. Thus the aggregate pricing equation is given by (see 
Appendix 8.8.4 for a detailed derivation of the dynamic pricing equation),

$$
\left(P_{i t}\right)^{1-\psi}=\rho\left(P_{i,(t-1)}\right)^{1-\psi}+(1-\rho)\left(P_{i t}^{*}\right)^{1-\psi},
$$

where $P_{t}^{*}$ is the optimally chosen price by the firms that have the chance to reset their price. The optimally chosen price will reflect the gross mark-up over the of the intermediate goods firm $\kappa$ 's ratio of the present discounted values of streams of nominal costs and outputs. This price dynamics captures the stickyness imposed on prices by the existence of firms without the opportunity of resetting the prices every period.

\subsection{Equilibrium configuration}

Now we can describe the equilibrium in the economy as follows.

1. The households in the $i$-th island (for all $i \in N$ ) maximizes their lifetime utility subject to their respective liquidity and budget constraints.

2. Firms maximize their profits in all islands by optimally choosing labor and capital inputs.

3. The market for internationally tradable goods clears.

4. The market for liquid assets clear.

5. The markets for the domestic final good (i.e. the non-tradables), intermediate goods (used in production of the final goods), labor and capital clear in all island.

To solve the model and get a closed-form solution, we make the following assumptions. The consumption bundle is assumed to have Cobb-Dauglas type form and the utility functions are logarithmic i.e. with unit elasticity of substitution, viz

1. $v_{1}(x)=\log (x)$ and $v_{2}(x)=\log (x)$,

2. $C_{i}^{F}=\prod_{j}^{N}\left(C_{i j}^{F}\right)^{\beta_{i j}}$ s.t. $\sum_{j}^{N} \beta_{i j}=1$.

These functional forms allow us to disentangle the domestic market (that is the market for non-tradables) from the international market (the market for tradables). In what follows, I first solve the model assuming non-stochastic preferences with a complete trade network i.e. where every island trades with all other islands. Later I extend the model to incorporate the cases of missing trade links and stochastic preferences.

The choice variables are consumption of tradable goods $\left(C_{i j}^{F}\right.$ for $\left.j=1, \ldots, N\right)$, consumption of domestic good $\left(C_{i}\right)$, labor input $\left(L_{i}(t)\right)$, capital holding next period $\left(K_{i}(t+1)\right)$ 
and liquidity demand for next period $\left(a_{i}(t)\right)$. The first-order conditions can be derived (see Appendix 8.8.1) easily giving us the trade-off between present and future consumptions,

$$
\begin{aligned}
\frac{1}{\beta} & =E\left[\frac{w_{i}(t)}{w_{i}(t+1)}\left(r_{i}(t+1)+1-\delta\right)\right], \\
\frac{B}{w_{i}(t) P_{i}(t)} & =E\left(\frac{\beta}{P_{i}(t+1) C_{i}(t+1)}\right) .
\end{aligned}
$$

Once the dynamic trade-off is pinned down, we can study the static decision of allocating liquidity to consumption of tradables versus non-tradables. As in Midrigan and Philippon [2011], asset holding evolves endogenously across islands. First, the same reference points out central monetary authority cannot possibly control the allocation of liquidity across locations within a country, and this is even more true for sovereigns within an monetary union. More importantly, in the present context, the islands will accumulate or reduce the nominal asset holding based on their preferences over non-tradables which determines the trade patterns across islands. Thus the liquidity holding is determined endogenously. In the later section, we show that not only it is intimately related to the trade matrix but also captures the centrality index very easily.

Now, we can state the first result concerning liquidity flow.

Proposition 1. In absence of any exogenous shock (preference or liquidity), the flow of liquidity across the islands is governed by a system of linear equations, $A(t+1)=\mathcal{T} A(t)$ where all elements of the transition matrix $\mathcal{T}$ are positive and $\mathcal{T}$ is column-stochastic that is the column-sums are 1 . This matrix $\mathcal{T}$ also captures the trade network across the islands.

The transition matrix $\mathcal{T}$ is the analogous to the Leontieff inverse of an input-output structure (as in Acemoglu et al. [2012], for example). The crucial difference is that it describes the linkages of the demand side whereas the Leontieff inverse describes the linkages of the supply side of the economies. Due to unit elasticity between consumption of tradable and non-tradable goods, the liquidity flow equations can be written independent of the domestic variables. Under such specifications, it turns out that the flow equations are also free of the stochastic endowment processes for the tradable commodities (see Appendix 8.8.3 for full details of the derivation). Consider the following matrix which includes all parameters of the utility functions of all islands, 


$$
Q=\left[\begin{array}{cccc}
\alpha_{1} \beta_{11} & \alpha_{2} \beta_{21} & \ldots & \alpha_{N} \beta_{N 1} \\
\alpha_{1} \beta_{12} & \alpha_{2} \beta_{22} & \ldots & \alpha_{N} \beta_{N 2} \\
\cdot & \cdot & \ldots & \cdot \\
\cdot & \cdot & \ldots & \cdot \\
\alpha_{1} \beta_{1 N} & \alpha_{2} \beta_{2 N} & \ldots & \alpha_{N} \beta_{N N}
\end{array}\right]
$$

The set of equations describing the liquidity flow $\left(A=\left(a_{1}, a_{2}, \ldots, a_{N}\right)\right.$ denotes the stocks of liquidity) can be written succinctly as a first order stochastic process

$$
A(t+1)=\mathcal{T}\left(A(t)+A^{\text {exo }}(t)\right) \quad \text { where } \mathcal{T}=\left(D_{1-\alpha}+D_{1-\alpha}(I-Q)^{-1} Q\right),
$$

where $D_{x}$ is a diagonal matrix with elements of vector $x$ along the diagonal. Note that $D_{1-\alpha}$ is a diagonal matrix of which the diagonal elements are the weights assigned to non-tradables in the utility functions of the islands. The first term on the right hand side of the above equation shows the flow of liquidity across islands and the second term shows the exogenous injection of liquidity in the system (by the central monetary authority). Thus we have a set of first order difference equations describing the system-wide flow of liquidity. Evidently, in absence of the exogenous injection of liquidity, the dynamics is given by $A(t+1)=\mathcal{T} A(t)$ as has been claimed in the above proposition.

To prove the second part, note that all elements of matrix $Q$ are positive and the column sums are less than one. A standard result from matrix algebra is that in such a case, $(I-Q)^{-1}$ exists and contains positive entries only (see e.g. Simon and Blume [2007], Theorem 8.13). Hence, all elements of $\mathcal{T}$ are positive. Finally, note that in absence of liquidity shocks the flow equation (Eqn. 9) has to be satisfied along with the identity that $\sum_{i} a_{i}(t+1)=\sum_{i} a_{i}(t)$ for all $\left\{a_{i}(t)\right\} \in \mathcal{R}_{+}^{N}$. In order that this conservation rule for aggregate liquidity is satisfied at all time points with all possible vectors of liquidity holding, the transition matrix $\mathcal{T}$ must be column stochastic. The intuition is that $\mathcal{T}$ behaves likes a Markov chain redistributing the existing stock of liquidity across islands.

Thus $\mathcal{T}$ is a well defined transition matrix which captures the relative weights that the islands assign to products of all islands as is evident from Eqn. 9 that $\mathcal{T}$ is an ensemble of the parameters of the utility functions of all islands. Since it captures the propensity to trade of individual islands with their respective neighbors, we calibrate it to the actual trade matrix. The interpretation is that $\mathcal{T}$ being column-stochastic, $\left\{\mathcal{T}_{i, j}\right\}$ represents the relative weights (of liquidity flow) that island $j$ assigns to all other islands $\{i\}$. This vector of weights can be found from actual (nominal flow) data on import basket of the island $j$. Note that flow of money would be opposite to flow of goods. Hence, outflow of money is equivalent to inflow of goods i.e. imports. 


\subsection{Dynamics of the model}

To study the dynamics of the liquidity flow, I first characterize a system with no exogenous injection of liquidity $\left(A^{e x o}(t)=\overrightarrow{0}\right.$ for all $\left.t\right)$. Note that if the islands have fixed, timeinvariant (non-stochastic) preferences, then the transition matrix $\mathcal{T}$ is time-homogeneous. However, we can extend the result to stochastic transition matrices as well which will be discussed later. First, we consider global convergence for non-stochastic transition matrix $\mathcal{T}$.

Proposition 2. Consider a set of $N$ islands such that the $\forall \in i, a_{i}(0) \in \mathbb{R}_{++}$and let us assume their interaction is described by $A(t+1)=\mathcal{T} A(t)$ with all possible pairs of islands trading. In absence of exogenous addition of liquidity, this dynamical system is globally stable and it has an unique fixed point. The rate of convergence is exponential.

To prove this proposition, we will use the following proposition from linear algebra.

Proposition 3. (Perron-Frobenius theorem) If all entries of a $n \times n$ matrix are positive, then it has a unique maximal eigenvalue. Its eigenvector has positive entries.

Note that for a stochastic matrix, the maximum eigenvalue is 1 . Thus the system converges to its corresponding eigenvector. Thus the dynamics shown by $\mathcal{T}$ has the same convergence properties. The intuition of the proof is very simple. Observe that in absence of addition of liquidity, this mechanism only reshuffles liquidity over the islands. Hence, the columns of the transition matrix must add up to 1 making it column stochastic. Then we apply Perron-Frobenius theorem to derive all the results stated in the above proposition.

Such long-run convergence of money holding among separated agents (spatially or in some other way), has also been noted other papers. For example, Williamson [2008] shows such a result in a model with segregated goods market with a set of agents connected to the financial institutions and a set of agents trading with the first group but unconnected to the financial sector. The 'trickle down' mechanism is similar in both the cases.

Note that the transition matrix $\mathcal{T}$ also gives us a network representation of the liquidity flow where each element of the matrix corresponds to the weight of edges existing between nodes (islands). This observation leads to the following proposition.

Proposition 4. The eigenvector centrality of the trade matrix is identical to the liquidity holding vector $A^{*}$ in the steady state.

As has been shown above, the dynamical system given by Eqn. 9 converges (in absence of any external shock; see proposition 2) asymptotically to an unique fixed point, say $A^{*}$. Thus in the steady state,

$$
A^{*}=\mathcal{T} A^{*}
$$


which implies that $A^{*}$ is the eigenvector associated with the largest eigenvalue of the transition matrix $\mathcal{T}$. Therefore, $A^{*}$ is also the eigenvector centrality of $\mathcal{T}$ by definition. Since, $\mathcal{T}$ captures the whole information of the trade matrix, we can calibrate it to the original export-import matrix and the eigenvector centrality found for the trade matrix (plotted in Fig. 1) can be matched by the solution of the dynamical system given by Eqn. 9 (without the shock).

The model allows us to capture the endogenous resilience of the islands to external liquidity shocks by the levels of liquidity held by them as well as by virtue of being positioned at the core, the islands can aggregate shocks coming from peripheral islands. Note that proposition 4 shows that a more central island holds a higher level of liquidity. Therefore, if the external shocks are generated from the same distribution, an island with higher centrality would show lower fluctuations in response to the shock as opposed to a less central economy. This is the first order effect. Proposition 5 shows that a centrally positioned island fluctuates less from external shocks as it has the advantage of aggregation. These two effects work together to reduce volatility of the core islands relative to the peripheral islands. This is formally stated in the following proposition.

Proposition 5. Consider a set of $N$ islands such that their interaction is described by $A(t+1)=\mathcal{T}\left(A(t)+A^{\text {exo }}(t)\right)$ with all possible pairs of islands trading and the exogenous shocks are i.i.d. Also assume that the domestic labor markets, final and intermediate goods markets are described by identical deep parameters in all islands. Then the volatility of the macro variables of an island are proportional to the volatility of growth rate of liquidity induced by the exogenous shocks. The variance of growth rate of liquidity stock of the $i-t h$ island in turn, is

(1) proportional to the variance of the exogenous liquidity shocks $\sigma_{a}$,

(2) inversely proportional to the square of eigenvector centrality $a_{i}^{*}$ and hence depends on the structure of the network $\mathcal{T}$

(3) an increasing function of size of the network $N$, product of average share $s_{i}$ of the island in the supply chain and the network-wide Herfindahl index $H$, and finally variance of the export portfolio $\sigma_{\mathcal{T}_{i}}^{2}$.

The following expression shows the fluctuations in the real variables in terms of the structure of the network and the shocks:

$$
\begin{aligned}
\sigma_{v_{i}} & \propto \sigma_{g_{i}} \\
& =\sqrt{N}\left(\frac{\sigma_{a}}{a_{i}^{*}}\right) \sqrt{\sigma_{\mathcal{T}_{i}}^{2}+s_{i} . H}
\end{aligned}
$$


where $\sigma_{v_{i}}$ denotes the fluctuations of the real variables viz. output, consumption, investment, wage and rental rate (all coming from the non-tradable sector). First, the positive relationship between volatility of money growth shocks and volatility of real variables are expected can be seen easily by considering the linearized system of equations describing the evolution of real variables in response to liquidity shocks (listed in Appendix 8.8.5). The relationship between fluctuation in nominal asset levels and those of real variables are linear in the sense that a bigger liquidity shock induces bigger fluctuations in real variables. Rest of the proposition depends on two broad channels. Proposition 4 (which shows that more central economies would hold bigger stock of liquidity and hence would show lower fluctuations in response to identical shocks) shows that central economies would show lower fluctuations in real variables. This is a first order effect. The second order effects arise due to the aggregation of liquidity shocks of downstream islands (to whom the island is exporting goods and hence receiving money from) as has been discussed above. The final level of volatility comprises both the effects.

A proof is given below. First I show that differences in volatility of domestic economies are what creates the differences in aggregate volatility across the islands. Note that by definition, real GDP of an island $i$ is defined as the sum of consumption, investment and net export evaluated at some fixed prices $(\{\bar{P}\})$, that is

$$
\begin{aligned}
G D P_{i} & =\left(\bar{P}_{i} \cdot C_{i}+\sum_{j} \bar{P}_{j}^{F} C_{j}^{F}\right)+I_{i}+\left(\bar{P}_{i}^{F}\left(Y_{i}^{F}-C_{i}^{F}\right)-\sum_{j \neq i} \bar{P}_{j}^{F} \cdot C_{j}^{F}\right) \\
& =\bar{P}_{i} \cdot Y_{i}+\bar{P}_{i}^{F} \cdot Y_{i}^{F} .
\end{aligned}
$$

Thus assuming i.i.d. process for the endowments of tradables (w.l.o.g. assume $\sigma_{Y_{i}^{F}}=0 \forall i$ ), the volatility of real GDP evaluated at the domestic price is $\sigma_{Y_{i}}$. Therefore, the volatility of the domestic income process is what differentiates the volatility of the aggregate income process across the islands. From Appendix 8.8.5, we know that in a log-linearized system the volatility induced on the real variables are proportional to the liquidity shocks given to the system. So the next step is to show why and how idiosyncratic liquidity shocks have different effects across islands.

From Eqn. 9 we can write the growth rate of the liquid asset of the $i-$ th island as

$$
g_{i}(t+1)=\frac{\sum_{j=1}^{N} \mathcal{T}_{i j} a_{j}(t)}{a_{i}(t)}+\frac{\sum_{j=1}^{N} \mathcal{T}_{i j} a_{j}^{e x o}(t)}{a_{i}(t)} .
$$


Therefore, the variance of the growth rate conditional on the current holding of liquidity is

$$
\begin{aligned}
\left.\sigma_{g_{i}}^{2}\right|_{a_{i}(t)} & =\frac{\sigma_{a}^{2}}{a_{i}^{2}(t)} \sum_{j=1}^{N} \mathcal{T}_{i j}^{2} \quad \text { where } \sigma_{a} \text { is variance of the } i . i . d . \text { shock, } \\
& =N\left(\frac{\sigma_{a}^{2}}{a_{i}^{2}(t)}\right)\left(\sigma_{\mathcal{T}_{i}}^{2}+\overline{\mathcal{T}}_{i}^{2}\right)
\end{aligned}
$$

where $\overline{\mathcal{T}}_{i}=\sum_{j} \mathcal{T}_{i j} / N$ is the average share of island $i$ in the downstream islands. The second term can be expanded further by dividing and multiplying by the sum of squared individual shares, $\sum_{i=1}^{N} \overline{\mathcal{T}}_{i}^{2}$ which is also the Herfindahl index $H$. Thus we get

$$
\left.\sigma_{g_{i}}^{2}\right|_{a_{i}(t)}=N\left(\frac{\sigma_{a}^{2}}{a_{i}^{2}(t)}\right)\left(\sigma_{\mathcal{T}_{i}}^{2}+s_{i} \cdot H\right),
$$

where $s_{i}$ is the share $\overline{\mathcal{T}}_{i}^{2} / \sum_{i=1}^{N} \overline{\mathcal{T}}_{i}^{2}$ of the $i$-th island and $H$ is the network-wide Herfindahl. Therefore, around the steady state the liquidity holding converges to the $a_{i}^{*}$ where $a_{i}^{*}$ is the eigenvector centrality of the $i$-th island and we get Eqn. 11. This completes the proof.

Example 1. A completely symmetric network: If we have a transition matrix with $\mathcal{T}_{i j}=1 / N \forall i, j \in N$, the standard deviation shows the usual $\sqrt{N}$ scaling as in the central limit theorem (see Acemoglu et al. [2012] for a parallel result in the production network),

$$
\sigma_{g_{i}}=\frac{1}{\sqrt{N}} \frac{\sigma_{a}}{a^{*}} \quad \text { where } a^{*} \text { is the common centrality. }
$$

Note that the centrality vector $\left\{a^{*}\right\}$ is invariant to any scaling. We multiply it by $N$ to make it comparable to the system size. Thus, we get

$$
\sigma_{g_{i}}=\frac{1}{\sqrt{N}} \sigma_{a}
$$

Example 2. Auturky: If $\mathcal{T}$ is an an identity matrix $I_{n \times n}$, the above formula shows that

$$
\sigma_{g_{i}}=\sigma_{a} \quad \text { which is the standard one-country model. }
$$

Example 3. Expansion of the network: To show the effects of an increase of size of the network, consider a fully connected, symmetric network $\mathcal{T}_{i j}=1 / N$ for all $i, j \in N$. Clearly if we add another another island to the network keeping it symmetric, one can directly apply Eqn. 17 to find that

$$
\sigma_{g_{i}}=\frac{1}{\sqrt{N+1}} \sigma_{a}
$$


Another way to derive the same would be to consider Eqn. 11. By increasing the size, there is a direct effect on volatility as the first term increases from $\sqrt{N}$ to $\sqrt{N+1}$. But by the same addition, we reduce the individual share $s_{i}$ goes down from $1 / N$ to $1 /(N+1)$ and the same happens with the Herfindahl $H$ indicating that inequality is reduced. The net effect of increasing size and reducing inequality finally boils down to an overall reduction of volatility.

Example 4. Central sector: This example shows that the negative effects of centrality on volatility can be exactly offset by positive effects of more openness. Consider the following the network

$$
\mathcal{T}=\left[\begin{array}{cccc}
\mathcal{T}_{1} & \mathcal{T}_{1} & \ldots & \mathcal{T}_{1} \\
\mathcal{T}_{2} & \mathcal{T}_{2} & \ldots & \mathcal{T}_{2} \\
\vdots & \vdots & \ddots & \vdots \\
\mathcal{T}_{N} & \mathcal{T}_{N} & \ldots & \mathcal{T}_{N}
\end{array}\right]
$$

Note that the dominant eigenvector is $\left\{\mathcal{T}_{1}, \mathcal{T}_{2}, \ldots, \mathcal{T}_{N}\right\}$. To make it comparable to the network size, we multiply the vector by $N$. Therefore, the volatility is given as

$$
\sigma_{g_{i}}^{2}=\frac{\sigma_{a}^{2}}{N^{2} \cdot \mathcal{T}_{i}^{2}} \sum_{j=1}^{N} \mathcal{T}_{i}^{2}
$$

which can be rewritten as

$$
\sigma_{g_{1}}=\frac{1}{\sqrt{N}} \sigma_{a} \quad \text { for all } i \in N .
$$

Thus it is the symmetry in the export portfolio that generates the usual central limit theorem. Note that this example covers Ex. 1 above. Assume that $\mathcal{T}_{1}>\mathcal{T}_{2}>\ldots>\mathcal{T}_{N}$. Clearly, a more central country is also more open as it has a higher share in the downstream countries' import baskets. Note that the variance of the export portfolio is zero for all. Thus the centrality effect is exactly offset by openness.

Next, we discuss the effects of Friedman's rule of constant money growth in the current context. Consider the equilibrium vector of liquidity holding $A^{*}$ without any exogenous liquidity shock. Clearly, the individual countries hold potentially different levels of liquidity $a_{i}^{*}$. The injection of liquidity adding to the already existing stock is given by a stochastic multiplicative process,

$$
a_{i}(t+1)=g_{i}(t+1) a_{i}^{*}
$$

As long as the the ratio of liquidity-holding across islands before and after the injection are identical (that is $a_{i}(t+1) / a_{j}(t+1)=a_{i}^{*} / a_{j}^{*}$ for all islands $i, j \in N$ ), there will be no flow 

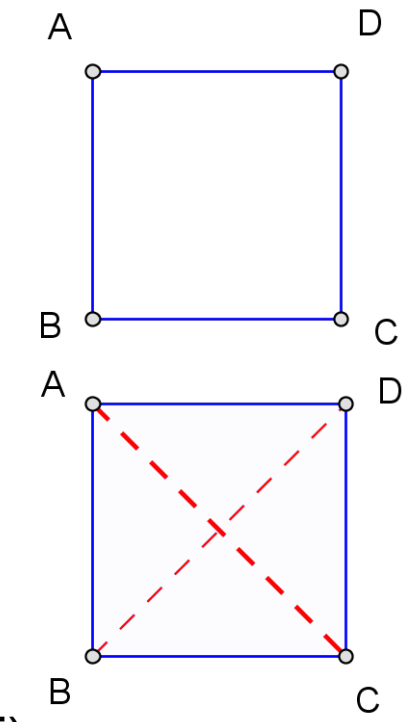

(i)

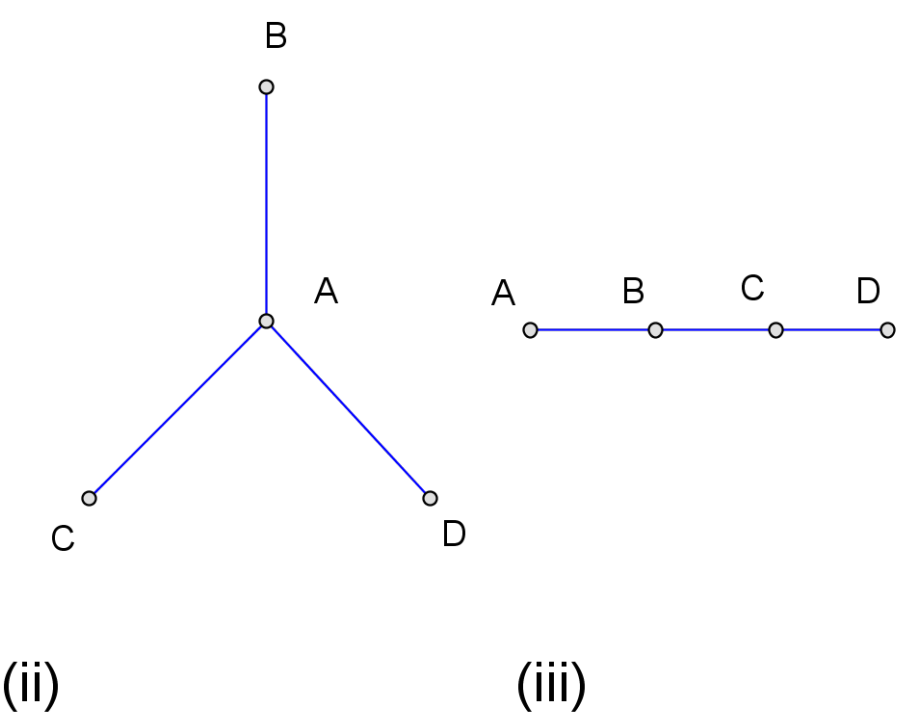

Figure 3: Different types of trade networks: (i) Dense (below) vs. sparse (above), (ii) coreperiphery (star), and (iii) linear.

of liquidity between the islands. Hence there will be no spill-over of effects across islands. This is formalized in the next proposition.

Proposition 6. If the growth rates of liquidity across the islands are exactly identical $\left(g_{i}(t)=\right.$ $g_{j}(t) \forall i, j$ and $\left.t\right)$, then there will be zero flow of liquidity across the set of islands described above and hence there will be no transmission of monetary shock from one island to another. However, if this knife-edge condition is violated, monetary shocks will be transmitted across islands and will have real effects.

Thus island-specific Friedman rules generate spill-over effects except in the case of identical growth rates.

\section{Examples: volatility on some symmetric networks}

An important dimension of the problem is to study the magnitudes of effects on volatility as a function of the network structure.

\subsection{Volatility of the islands: dense versus sparse networks}

Below we consider two path-connected networks with four nodes each, one fully connected and the other does not have the internal edges (see Fig. 3, panel (i)). The reason we need at 


\begin{tabular}{|l|l|l|l|l|l|l|}
\hline Type & $\mathrm{Y}$ & $\mathrm{C}$ & $\mathrm{K}$ & $\mathrm{H}$ & $\mathrm{w}$ & $\mathrm{r}$ \\
\hline Auturky & 0.0174 & 0.0049 & 0.0085 & 0.0256 & 0.0051 & 0.0270 \\
\hline Sparse & 0.0121 & 0.0046 & 0.0072 & 0.0164 & 0.0046 & 0.0174 \\
\hline Dense & 0.0110 & 0.0043 & 0.0068 & 0.0144 & 0.0044 & 0.0153 \\
\hline
\end{tabular}

Table 1: Standard deviations of endogenous variables on sparse and dense networks (see Fig. 3, panel $(i))$.

least four nodes is that with less than four nodes it is impossible to draw a sparse network with symmetric connections between nodes. In both cases, the nodes (islands) are described by an identical set of parameters (shown in Table 4). Consider the following symmetric transition matrices:

$$
\mathcal{T}^{d}=\left[\begin{array}{cccc}
1 / 3 & 2 / 9 & 2 / 9 & 2 / 9 \\
2 / 9 & 1 / 3 & 2 / 9 & 2 / 9 \\
2 / 9 & 2 / 9 & 1 / 3 & 2 / 9 \\
2 / 9 & 2 / 9 & 2 / 9 & 1 / 3
\end{array}\right], \mathcal{T}^{s}=\left[\begin{array}{cccc}
1 / 3 & 1 / 3 & 0 & 1 / 3 \\
1 / 3 & 1 / 3 & 1 / 3 & 0 \\
0 & 1 / 3 & 1 / 3 & 1 / 3 \\
1 / 3 & 0 & 1 / 3 & 1 / 3
\end{array}\right]
$$

$\mathcal{T}^{d}$ shows a symmetric dense network where all edges exist whereas $\mathcal{T}^{s}$ shows a symmetric sparse network which forms a cycle (undirected) with missing edges between nodes. Fluctuations of the variables can be compared to see the effects of the changes in network structure. A comparison with single island case is also provided (see Table 1).

Note that if an island is completely disconnected from the rest of the graph, then it has no scope of dissipating the fluctuations. On the other hand, by being connected to other islands, two opposite effects take place. The island is no longer immune to fluctuations of its neighbors, but it can also mitigate fluctuations by transferring its own shocks to its neighbors. Given a fully connected (dense) network, shocks are dissipated better than on a sparse network where some of the possible edges are missing. This is evident from the table showing standard deviations of the real variables (output, consumption, capital, labor hour, wage and rental rate). But overall, effects of trade integration is beneficial in terms of volatility. For simulation purpose, I have used the values given in Table 4 except for standard deviation of liquidity growth shock which is set to 0.00135 .

\subsection{Star network}

Next, we consider a core-periphery network structure (see Fig. 3, panel (ii)). More precisely, we assume there is one economy at the core of the network and there are three economies at the periphery i.e. the core trades with all the peripheral economies whereas the peripheral 


\begin{tabular}{|l|l|l|l|l|l|l|}
\hline Type & Y & C & K & H & w & r \\
\hline Core & 0.0104 & 0.0043 & 0.0067 & 0.0132 & 0.0043 & 0.0141 \\
\hline Periphery & 0.0118 & 0.0045 & 0.0070 & 0.0150 & 0.0045 & 0.0160 \\
\hline
\end{tabular}

Table 2: Standard deviations of endogenous variables on a core-periphery network (see Fig. 3 , panel $(i i)$ ) with identically distributed shocks.

\begin{tabular}{|l|l|l|l|l|l|l|}
\hline Type & Y & C & K & H & w & r \\
\hline Core & 0.0113 & 0.0043 & 0.0068 & 0.0150 & 0.0043 & 0.0160 \\
\hline Periphery & 0.0134 & 0.0045 & 0.0072 & 0.0178 & 0.0045 & 0.0188 \\
\hline
\end{tabular}

Table 3: Standard deviations of endogenous variables on a core-periphery network (see Fig. 3, panel $(i i))$ with proportional shocks.

economies do not trade amongst themselves. Table 2 shows the volatility of the corresponding macro variables. Evidently, the core fluctuates less compared to the periphery. This is not surprising as we have already seen that a more central island should fluctuate less. However, two effects are working here. The central economy $A$ gathers more liquidity and hence the liquidity shocks are lower in percentage terms. At the same time, it is better diversified which also contributes to lower volatility. To suppress the effect of centrality, we can give proportional liquidity shocks to the economies. Thus only the diversification channel works and still the core fluctuates less than the periphery (see Table 3). Due to bigger shocks volatility increases for all variables.

\subsection{Spill-over effects}

In this section, I show how the effects of a shock spread across the network via the spill-over effects of liquidity due to trade. Any injection of liquidity in a fully connected network, will have immediate repercussions on the domestic markets of all islands. However, if we consider a only path-connected network, then the spill-over effects are clearly not immediate. This can be best describe by considering a linear network (a chain).

For simplicity, we assume that there are 4 islands forming a linear network (see Fig. 3, panel (iii)). We give a small growth rate shock at the left-most node of the network and study the impulse response functions of domestic macro-variables of all islands for describing the spill-over effects. From Fig. 4, it is evident that the shock sends a ripple through the network and the further the island is from the source of the shock, the lesser is the effect on the variables in terms of magnitudes of fluctuations. In a very large network, it will be interesting to see the extent of the spill-over effects which we ignore for the current purpose 

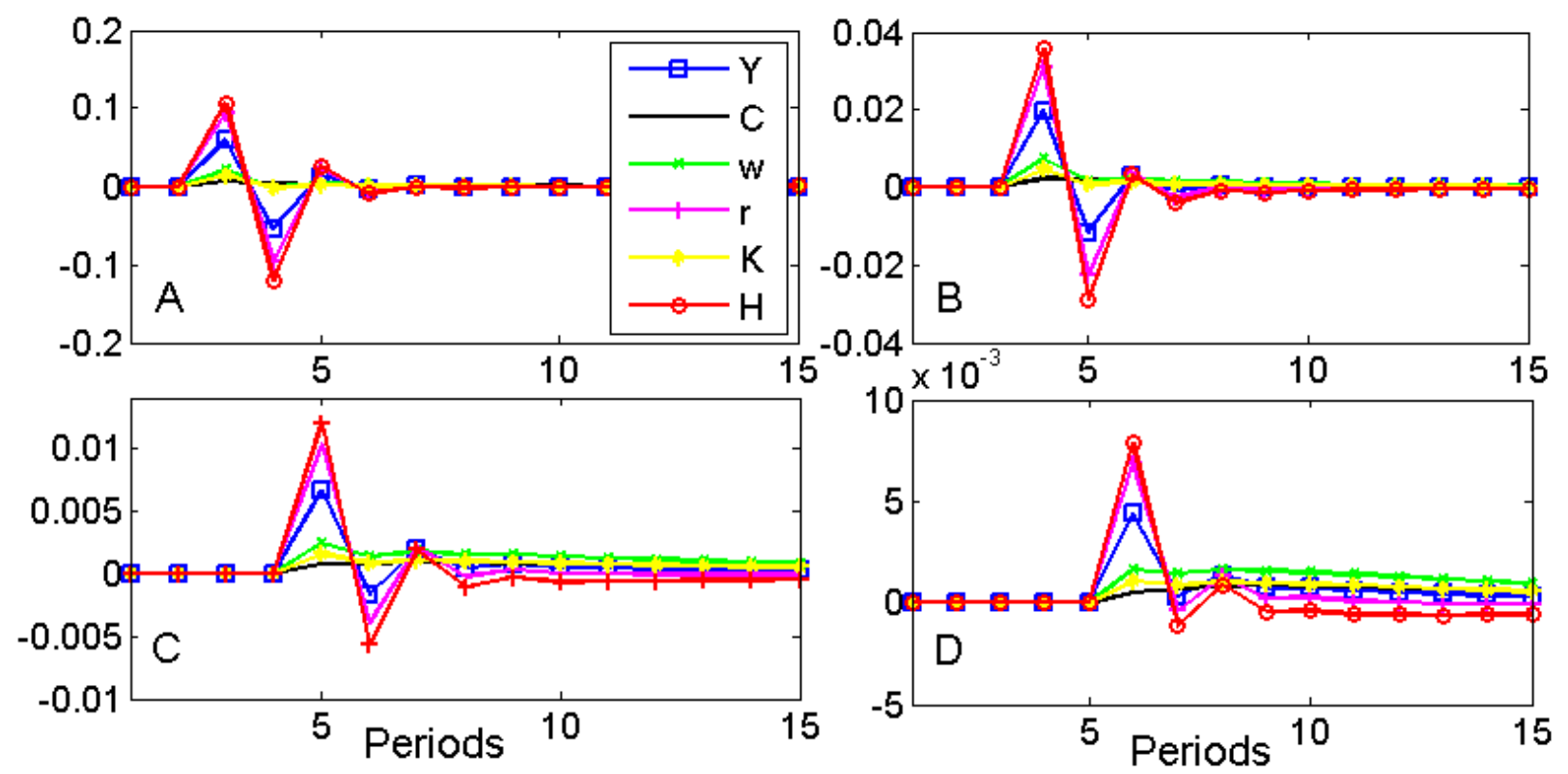

Figure 4: Shock propagation in a linear network (see Fig. 3, panel (iii)) : impulse response functions of a 0.01 liquidity growth rate shock to the left-most node $A$. Up-left panel: shock hits island $A$. Up-right panel: the second island $B$ in the chain is affected at a unit time lag. Down-left panel: the third island $C$ is affected at two units time lag. Down-right panel: the fourth island $D$ receives the shock at three units time lag. This shows a clear description of the time-delayed propagation of shock from the source throughout the network. Another important point to notice is that the further the shock travels from the origin, the weaker it becomes in terms of degree of fluctuations it creates. 


\begin{tabular}{|l|l|l|}
\hline Description & Parameter & Value \\
\hline Disutility parameter & $B$ & -2.5805 \\
Discount factor & $\beta$ & 0.99 \\
Rate of depreciation & $\delta$ & 0.025 \\
Share of capital in output & $\theta$ & 0.36 \\
Degree of price stickyness & $\rho$ & 0.75 \\
Mark-up factor & $\psi$ & 11 \\
St. dev. of TFP shock & $\sigma_{y}$ & 0.00178 \\
AR(1) coeff. of TFP shock & $\gamma_{y}$ & 0.9 \\
St. dev. of liq. growth rate shock & $\bar{\sigma}_{a}$ & 0.04 \\
AR(1) coeff. of liq. growth rate shock & $\bar{\pi}$ & 0.5 \\
\hline
\end{tabular}

Table 4: Values of the parameters describing the islands. The standard deviation of the growth rate shock has been calibrated to match the average volatility of income of the sample of countries.

(see Sec. 8.9 for a discussion on spill-over effects in statistically different large networks).

In the next section, we calibrate the model and study its quantitative implications.

\section{$5 \quad$ Quantitative results}

So far we have described the flow of nominal assets on the network. As the households are liquidity constrained, any such inflow or outflow will have repercussions in the markets for non-tradables. To analyze the extent of these effects in details, we log-linearize the full system of equations (see Appendix 8.8.5 for the original set of equations and 8.8.7 for the log-linearized version of the same) describing the domestic market and the behavior of the system around the steady state can be discussed. Note that there are two possible sources of fluctuations: liquidity shock and productivity shocks. We consider that all islands receive identically distributed productivity and liquidity shocks (proportional to the liquidity holding of the least central island to ensure that the shocks are small enough so that loglinearization is meaningful). Due to asymmetries in the connectivity of different islands in the trade network, the islands will hold different stocks of liquidity in steady state (given by their respective eigenvector centrality; see proposition 4). Thus similar liquidity shocks will induce different responses across islands.

Unless otherwise mentioned I use the parameters as described in Table 4 to solve for the domestic economy for all islands. Fig. 5 shows the simulated volatility of islands (described by equations in Appendix 8.8.5) by calibrating $\mathcal{T}$ to the trade matrix. All islands receive identically distributed productivity and liquidity shocks. The first one contributes equally 


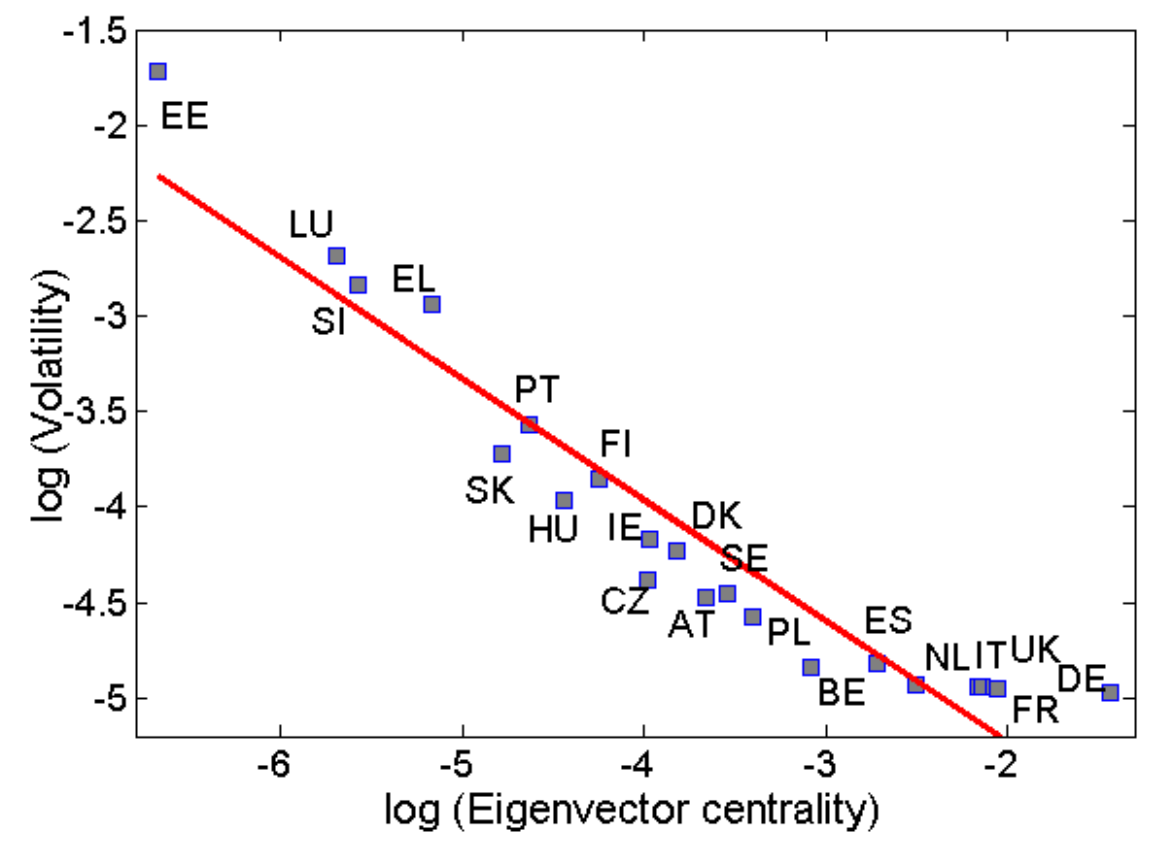

Figure 5: Log of simulated volatility of countries in Europe is plotted against log of eigenvector centrality by calibrating intra-Europe trade network.

to volatility of all islands whereas the liquidity shock affects the islands very differently as countries with lower centrality show more fluctuations. Next, we plot the simulated volatility and first order and second order (Fig. 8) centrality. In all cases, the negative relationship prevails (see Sec. 8.3 for empirical justification). For the list of names of the countries with abbreviations used in the figures see Table 9. Six countries have been dropped due to their marginal presence in the trade network.

\subsection{Working of the model}

The following three steps allow us to understand the negative relationship between centrality and volatility.

\subsubsection{More central islands are more liquid}

This comes directly from proposition 4. To understand this result, one can think of the following experiment. Consider $N$ islands connected to each other with varying weights of edges. Time is discrete. Introduce some Dollar bills on those islands. At each point of time, each Dollar bill chooses one of its neighboring islands to move to with probability proportional to the weight of the respective edges i.e. connections. If this system is allowed 


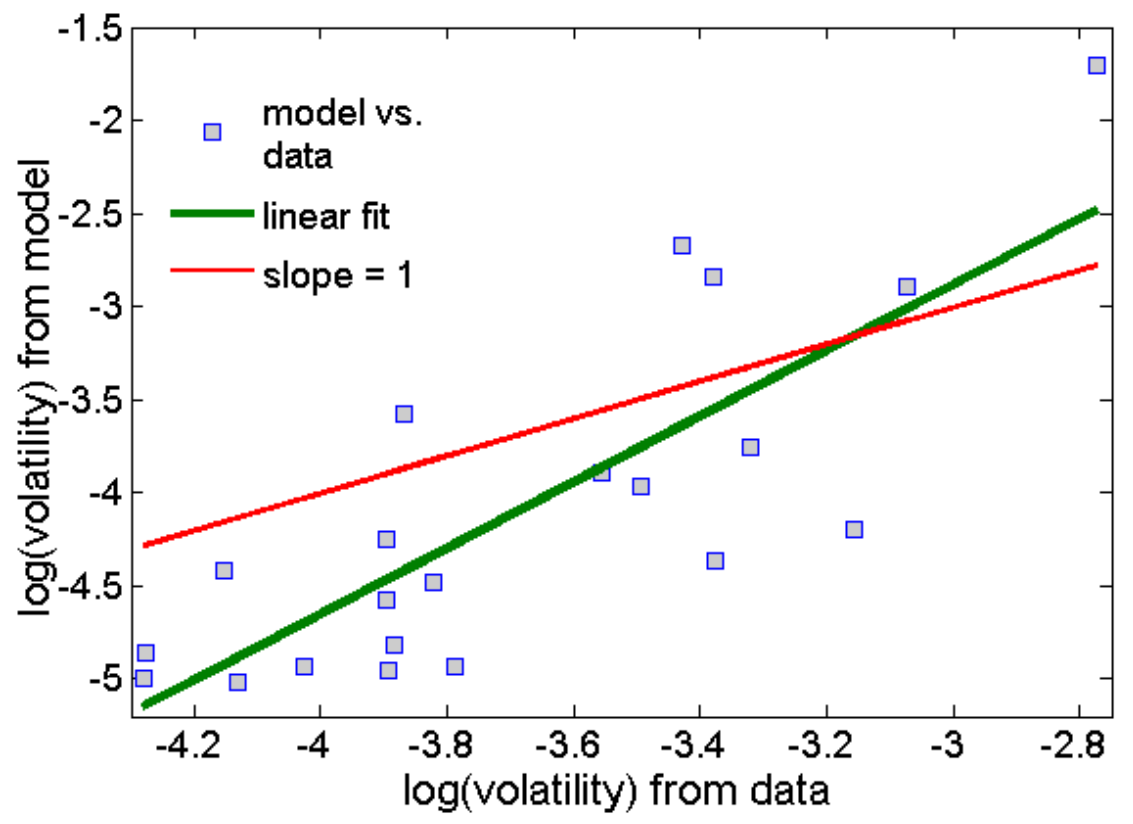

Figure 6: Model diagnostics: volatility of output from real data and simulation are plotted along with a straight line with slope 1 (thin red line). The fit of the model with data has a slope of 1.77 (thick green line).

to evolve, over time the distribution of Dollar bills settle down to a particular distribution which can be described as the steady state distribution.

Such a distribution has two properties. First, the distribution itself is pinned down by the edge-weights i.e. the probabilities that were used to move the Dollar bills from one island to another. Second and more important for our purpose is that the number of bills or the amount of money in each island will be proportional to its centrality. In other words, a more central island will accumulate a larger number of bills. This feature is also seen in case of bank to bank lending scenario and has been studied in e.g. Bech et al. [2010].

\subsubsection{Bigger liquidity shocks generate bigger responses}

The way liquidity growth rate shock affects each island follows a standard mechanism. Consider the log-linearized domestic flow budget constraint (see Appendix 8.8.7 for the full set of log-linearized system of equations)

$$
\bar{Y} \tilde{Y}_{t}+(1-\delta) \bar{K} \tilde{K}_{t}-\bar{K} \tilde{K}_{t+1}-\frac{\bar{a}}{\bar{P}} \tilde{a}_{t}+\frac{\bar{a}}{\bar{P}} \tilde{P}_{t}=0
$$

where the index for the $i$-th island is dropped for clarity. Note that prices are sticky and the period $t$, the capital stock is given. Hence, any positive growth shock to assets will lead 
to an increase in output to maintain the equality. Since, capital is fixed, this must be the result of an increase in the labor force. Therefore, wages must increase to attract more labor. A larger labor force increases the marginal product of capital and correspondingly leads to an increase in rental rate as well. Since nominal assets are neutral in long-run, the whole process is accompanied by a gradual catch-up process of price so that in long-run the economy returns to the stationary state. The important point to note is that the whole domestic side of an island is segregated from the other side of the island (which engages is foreign trade) except through the channel of assets. Thus any foreign trade leads to inflow/outflow of assets through an island which has repercussions in the domestic economy by altering the available liquidity. Since the network structure determines how liquidity flows through the islands, the same eventually determines how the islands (i.e. their domestic side) respond to the liquidity shocks.

\subsubsection{More central island fluctuate less}

Combining the above two mechanisms, we see that a more central island fluctuates less. The diversification argument in Eqn. 4 also holds true. But in real data it is over-shadowed by the centrality. We have carried out regression exercise to explain volatility of three macroeconomic variables viz. output, consumption and capital formation as functions of standard explanatory variables like trade openness, credit to GDP ratio, value of stocks traded as a fraction of GDP, ratio of FDI to GDP along with liquidity available and centrality. As can be seen from Table 5, more central economies do fluctuate less and the economies which are more liquid, they also tend to fluctuate less. If we incorporate size or GDP in the regression, then the exercise becomes insignificant due to high correlation of size with centrality. Therefore, we use an instrument to disentangle the effects of centrality on volatility. Specifically, we construct the geographical network across the countries considered and construct the geographic centrality index of all countries (see Mayer and Zignago [2011] for details on the source of data). This index is used as an instrument for trade centrality. The underlying idea is that geographical advantage imparts trade advantage. On the other

hand, it will be orthogonal to size of the economy. Table 7 confirms the claim that centrality is negatively related to volatility. The results are quantitatively similar with robust standard errors and sample size adjustments.

\section{$5.2 \quad$ Fit of the model}

I have plotted model's prediction with real data in Fig. 6. As can be seen from the figure, the slope of the fit is 1.77 whereas in the ideal scenario the slop should be equal to 1 . 
The average volatility is matched across the islands by calibrating the liquidity growth rate shocks. Given the higher slope, we see that the the model predicts a bigger spread of crosssectional volatility. Peripheral economies show more volatility than their counterparts in the data and the core countries show less volatility is there in the data. Thus the model captures the negative relationship well even though it does not replicate the exact slope between centrality and volatility.

\subsection{Cross-sectional distribution of assets}

Due to the assumption of the cash-in advance constraint the model implies quantity theory of money. Since the model generates a liquidity flow network across a set of islands, in equilibrium the model implies that per-capita nominal GDP is equal to per-capita stock of liquidity. Thus the quantity theory holds at cross-section i.e. an $N$-country version of the quantity theory is obtained (see also Midrigan and Philippon [2011]). 

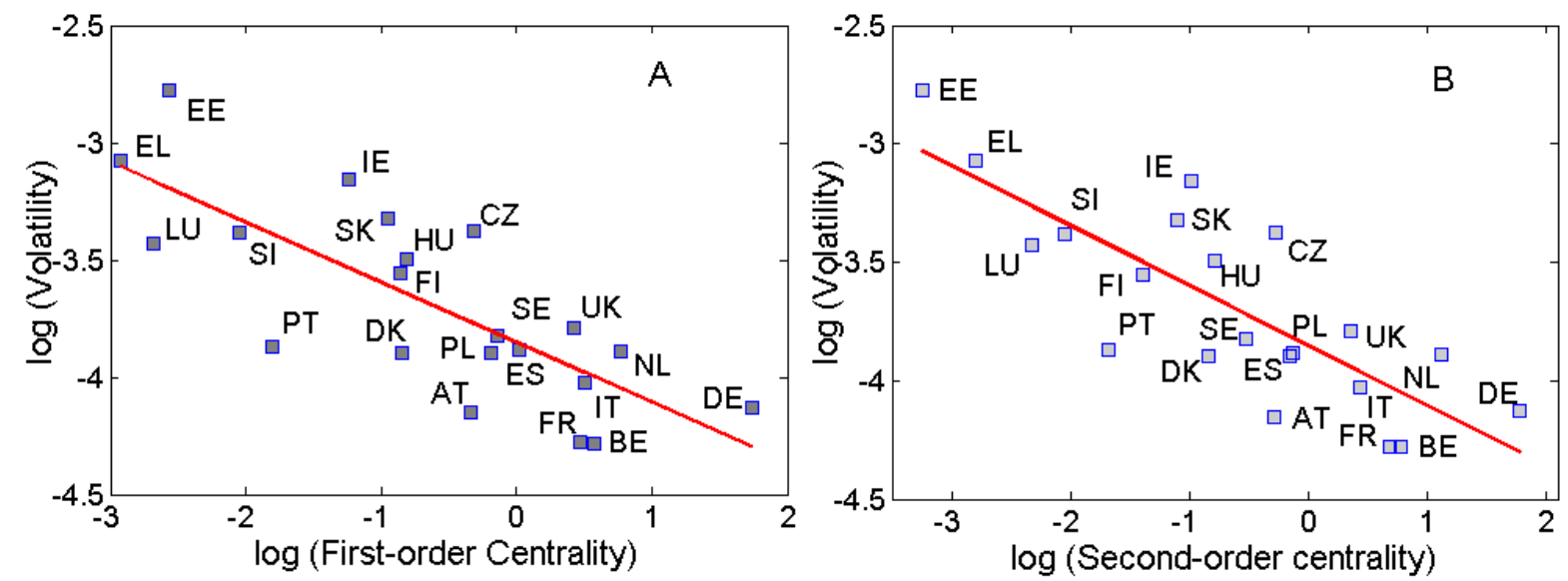

Figure 7: Exploration in actual data. Panel (A): Log of volatility of countries in Europe is plotted against log of first-order centrality of the countries in the intra-Europe trade network. Panel (B): Same plotted w.r.t. second order centrality.
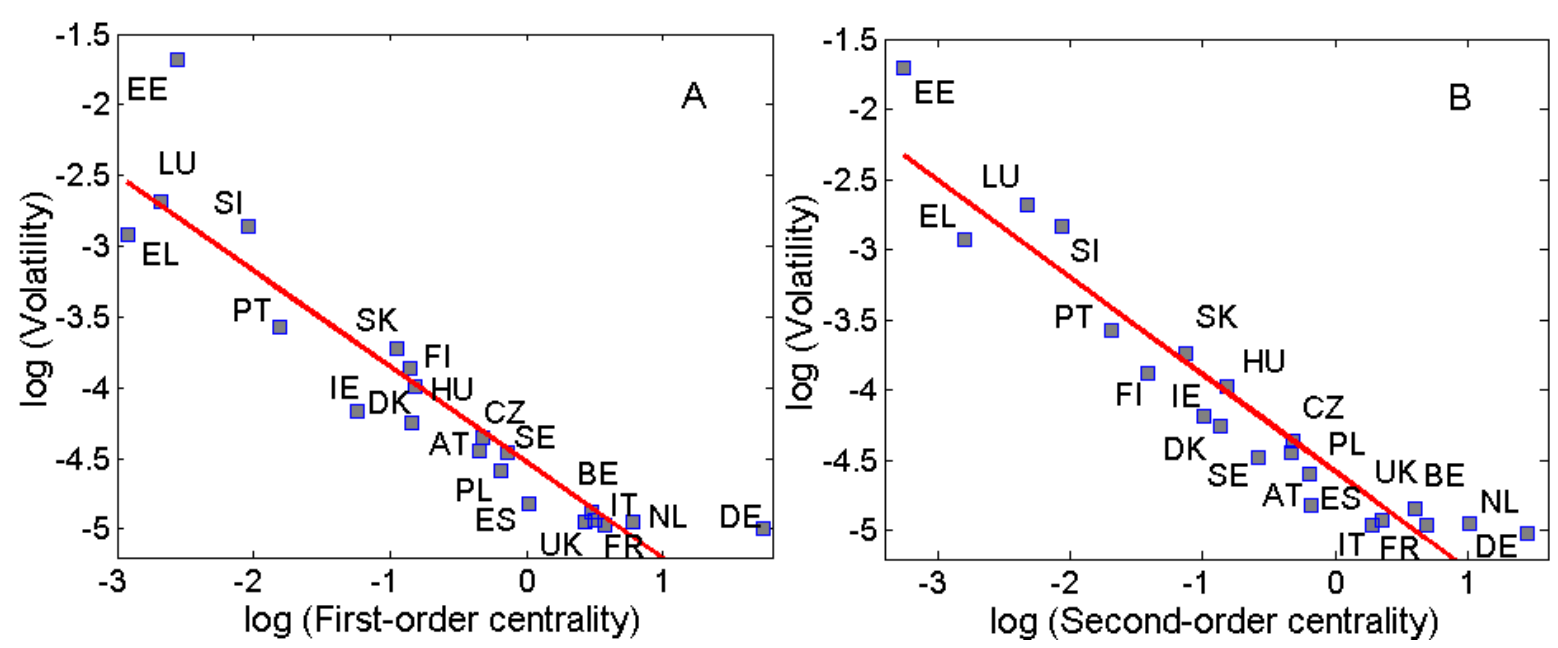

Figure 8: Simulation results. panel (A): Log of simulated volatility of countries in Europe is plotted against log of first-order centrality of the countries in the intra-Europe trade network. Panel (B): Same plotted w.r.t. second order centrality. 
Note that by summing over liquidity constraints for all islands in equilibrium, we have

$$
P C=A_{t o t}
$$

where $A_{\text {tot }}$ is the aggregate liquidity in circulation, $C$ is the aggregate consumption of nontradables and $P$ is a suitably defined price index. Since consumption is endogenously determined as a function of output (through the consumption-savings trade-off), we can rewrite the above equation as

$$
P Y=A_{t o t} V,
$$

where $Y$ is the aggregate output and $V$ is the velocity of money, defined as inverse of average propensity of consumption. Since the model implies a flow network of money across the islands, we can give a network theoretic interpretation of velocity.

Expected velocity of money To pin down the velocity of money, we can again think of a collection of $N$ islands. Let us begin with the smallest bit of liquidity (e.g. a Dollar bill) transferred to one island in a fully connected, finite network with constant edge-weights described by an ergodic Markov chain $\mathcal{T}$. Note that the bill essentially performs a asymmetric random walk on the network. Then the expected return time (the time required to come back to a particular island $j$ starting from the same) is

$$
\tau_{j j} \sim \frac{1}{a_{j}}
$$

where $a_{j}$ is the $j$-th element of the corresponding stationary distribution (of $\mathcal{T}$ ). Let $j$ be an island (node) and $c_{j}$ denote the expected number of steps to visit every island of the network starting at $j$, also known as the cover time. In general, we can provide the following bounds on the cover time. For a general trade network with $N$ islands defined by the Markov chain $\mathcal{T}$,

$$
c_{j} \leq 4 N \times E, \quad \text { where } E \text { is the number of edges. }
$$

Since for a dense network, $E$ would be in the order of $N^{2}$, the cover time would be $4 N^{3}$. In some special cases, the bound is tighter (see Appendix 8.10).

\section{Model perturbation}

In the following, we generalize the above results to include more elaborate network structures. Note that the transition matrix $\mathcal{T}$ is also the adjacency matrix of the corresponding network 
showing how the islands are connected to each other. Each element $\mathcal{T}_{i j}$ gives the weight of the link between islands $i$ and $j$. Therefore, to discuss both the trade pattern and the dynamics of the system, we can use the properties of the transition matrix $\mathcal{T}$.

So far we assumed all pairs of islands trade with each other, which effectively means that all islands attach positive weights in the utility functions to all goods produced in other islands. First, we relax that assumption allowing the possibility that some island may actually not trade with some other island i.e. some islands may attach zero weight (limiting) to production of some islands, which makes the transition matrix semi-positive. Before stating the results, we need to define a few terms. A walk in a network $G \equiv(N, T)$ refers to a sequence of nodes, $n_{1}, n_{2}, n_{3}, \ldots, n_{K}$ such that $n_{k} n_{k+1} \in T$ for each $k \leq K$ and the length of the walk is the number of links in it, or $K-1$. A path in a network $(N, T)$ is a walk such that all the nodes are distinct.

Definition 3. A network $G \equiv(N, T)$ is path-connected if there is a path in $(N, T)$ between every pair of nodes $i$ and $j$.

The degree of a node $i$ in a network $(N, T)$ is the number of neighbors that $i$ has in the network, so that $d_{i}(T)=\left|N_{i}(T)\right|$. In the present context, the degree of an island refers to the number of islands that it trades with such that the weight attached in the utility function is strictly positive (hence the edges also have strictly positive weights).

The following proposition establishes a convergence result for trade networks with possibility of zero weights.

Proposition 7. If the trade network is path-connected and the associated transition matrix is aperiodic, there exists an stationary distribution of assets.

To prove the above proposition, we use the following basic convergence theorem of Markov chains.

Proposition 8. Let $\mathcal{T}$ be the transition matrix of a Markov chain that is aperiodic and irreducible. Then there exists a stationary probability distribution over the states.

Along with it, note that irreducibility of the chain is equivalent to the underlying network being path-connected. Proposition 7 sets a limit on sparseness of the transition (or trade) matrix. It shows that as long as the assumption of path-connectedness is retained i.e. given any two islands there exists a path connecting them however long that might be, we can appeal to the same set of results to study the dynamics.

Example 5. Panels (ii) and (iii) of Fig. 3 are examples of path-connected network. 
Example 6. Consider an economy with two islands with the transition matrix,

$$
\mathcal{T}=\left[\begin{array}{ll}
0 & 1 \\
1 & 0
\end{array}\right]
$$

Thus if the islands start with liquidity-holding $a_{1}$ and $a_{2}$, both of them will have a sequence of alternating levels of liquidity-holding viz $a_{1}, a_{2}, a_{1} \ldots$ Therefore, to ensure convergence, we need aperiodicity. Note that without this condition, the liquidity shocks $\left(a_{1} / a_{2}\right.$ or $\left.a_{2} / a_{1}\right)$ will be periodic and hence, so will be the corresponding fluctuations in the real variables. Such fluctuations are evidently endogenous, but since they are periodic, it is not a particularly realistic scenario.

Since path-connectedness of the trade network appears to a necessary condition for convergence of the system, here we provide the necessary and sufficient conditions for having a path-connected network with exogenously imposed degree sequences. Let us denote the degree (connectivity) of the $i$-th island by $d_{i}$. Thus the degree sequence of all islands is given by $d_{1}, d_{2}, \ldots, d_{N}$. There are two conditions;

For realizability: for $1 \leq k \leq N-1$,

$$
\sum_{i=1}^{k} d_{i} \leq k(k-1)+\sum_{i=k+1}^{N} \min \left\{k, d_{i}\right\}
$$

and for connectedness:

$$
\sum_{i=1}^{N} d_{i} \geq 2(N-1)
$$

Erdos-Gallai theorem (Choudum [1986]) states that these two are necessary as well as sufficient conditions to generate a connected network satisfying a given degree sequence.

Next, we consider stochastic preferences which means the parameters of the utility functions describing the relative weights to consumption of different goods (tradables and nontradables) can vary over time. Thus the transition matrix now becomes time-nonhomogenous $\mathcal{T}_{t}$.

Assume that $\mathcal{T}_{t}$ are stochastic matrices for all $t$ and are independently and identically distributed. Then we can apply following proposition for ergodicity of time-nonhomogeneous Markov chain.

Proposition 9. (following Thm 1.4, Bruneau et al. [2010]): If the elements of the timenonhomogenous transition matrix $\mathcal{T}_{t}$ are strictly positive with positive probability, then the Markov chain converges in exponential time. 
See Bruneau et al. [2010] for a detailed proof and discussions.

\section{Conclusion}

In this paper, I have shown that centrality of an economy in the trade network has an important effect on macroeconomic volatility. It provides a complementary approach to the existing literature on determination of volatility.

I have used the standard neo-Keynesian DSGE framework to model the domestic economy of each individual country. These countries taken together constitute a flow network of liquidity. A Calvo-type staggered-pricing set-up is used in the form of nominal friction to generate the long response time of the macroeconomic variables. The additive separability of the tradables and non-tradables in the utility function allows me to disentangle the international market from the domestic market. Thus their dynamics can be studied separately. It has a huge implication in the sense that effectively any inflow/outflow of liquidity due to trade in the international market changes the liquidity available to be spent in the domestic economy. At the global level, total supply of liquidity is determined by an exogenous body (the central bank). Below I discuss validity of several assumptions made in the model and possible extensions of the model.

In the present paper, the network is generated from the demand side. Due to the assumption of differentiated products indexed by their origins and preferences defined over a bundle

of tradables, we can express the trade network as a function of the parameters in the utility functions only. Thus it is complementary to the input-output approach which generates the network from the parameters of the production functions (see e.g. Acemoglu et al. [2012]). However, we can easily interpret the model in terms of an input-output framework. Think of the tradables being intermediate inputs and the countries trade those intermediate inputs in a perfectly competitive international market. Assume that each country has a domestic technology that can bundle those intermediate inputs costlessly and convert it into a final, non-storable consumption good which the household consumes. Thus the flow network will be in terms of importing and exporting raw materials. The same framework as has been discussed above, can be used to model that scenario except that the parameters of the bundling technology in the production function proposed above will describe the network instead of the same in the utility function.

The asset side of the model is simple. There is one internationally tradable nominal asset in the model. Note that in addition I have also considered domestic capital stock which allows households to smooth consumption streams. Introduction of internationally tradable bond would make the problem intractable to solve as the portfolio determination 
becomes problematic in the present formulation. It is beyond the scope of the present work. Also, the presence of a single nominal asset (as opposed to country-denominated nominal assets) is a simplifying assumption allowing us to circumvent the problem of exchange rate determination in case of multiple currencies. An alternative interpretation of the model in case of countries not having a common currency, is that we consider vehicle currency which is issued by a third party but used widely in trade e.g. Dollar. Another way to see the model is to consider multiple currencies with fixed exchange rates and perfect substitutability between the currencies. A extension of the model can be considered with imperfectly flexible exchange rates so that the friction causes changes in liquidity holding of countries due to a liquidity shock. However, the underlying structure of the model would remain the same as has been considered above.

Finally, in a recent contribution Jackson et al. [2014] consider cross-holding of debt in a setting close to Eqn. 9 augmented with nonlinear features and studies cascading failures due to shocks. The model presented here is linear in nature allowing for complete description and hence is useful for studying spill-over effects. Thus it provides a complementary approach to studying the problem of spill-over effects through linkages across countries. 


\section{Appendix}

\subsection{Relation to the literature}

This paper is related to three strands of research: (i) the newly established macroeconomic models with explicit network structure and non-trivial, asymmetric interaction between the elements of the network, (ii) monetary economics (iii) effects of trade on domestic macroeconomic volatility. The recent boost in the explicit application of the network theory to explain macroeconomic volatility started with Acemoglu et al. [2012]. This study showed that the industries in U.S. are far from equal in terms of connectivity to other industries. Technically, the degree distribution has been showed to have a fat (power law) tail thus indicating significant asymmetries in the ability to dissipate or propagate idiosyncratic shocks. This phenomenon provides a basis to explain aggregate shocks arising from such microeconomic shocks. An immediate precursor of this idea can be found in Gabaix [2011], which showed if the firm size distribution has a fat tail i.e. described by a power law, then the idiosyncratic shocks to the firms explains a large fraction of the total fluctuations. These contributions marked a prominent departure from the earlier way of modeling with their emphasis on the asymmetries at the level of economic organizations or entities and provided a resolution to the debate of whether organizational linkages are important (see Dupor [1999] and Horvath [1998]). However, it is not clear whether it is the extreme differences in size (as in Gabaix [2011]) or the connectivity (as in Acemoglu et al. [2012]) that matters most for explaining volatility, as it is difficult to differentiate between these two effects since larger economic entities usually have larger connectivity as well. This problem has been discussed in the context of macroeconomic volatility induced by international trade on countries, as well (see for example Giovanni and Levchenko [2012]). One possible way out to disentangle the effects is to consider cross-correlation between the macro-variables of countries. If it is only size-driven then that does not imply anything about the macro-variables being correlated. On the other hand, given the level of comovement of macro-variables across countries, the spill-over effects of international trade (Kose et al. [2003]) constitute a better explanation.

The present contribution takes the network theoretic point of view on volatility proposed by Acemoglu et al. [2012], but differs in focus. As opposed to explaining why different nodes contribute differently to aggregate fluctuations, I explain why different nodes may show different levels of volatility because of the asymmetries in connectivity. In related contexts, the characteristics and implications of such large scale economic networks have been investigated extensively ${ }^{9}$. For example, Oberfield [2013] and Chaney [2014] studied

\footnotetext{
${ }^{9}$ For economic applications (mostly microeconomic), see Vega-Redondo [2007], Goyal [2009], Jackson [2010].
} 
endogenous evolution of the input-output network and export-import network, respectively. The effects of multilateral linkages between firms on a have been studied Jackson et al. [2014] and Bigio and Lao [2013] which shows non-negligible effects on aggregate dynamics. Kelly et al. [2013] analyzed a model of firm volatility based on customer-supplier connectedness to explain common movements in firm-level volatility. Ghiglino and Goyal [2010] studied formation of equilibrium prices, allocation and welfare in a trade network of agents with exogenous endowment processes. An important finding of their work is that a single statistic of the network viz., centrality, turns out to be the crucial factor in determining the agentspecific equilibrium outcomes. This is also featured in the present model and I show that there is a one-to-one relationship between centrality and macroeconomic volatility.

The effects of trade integration on volatility is inconclusive (Burgess and Donaldson [2012]). While studies like Cavallo and Frankel [2008], Bejan [2006], Martin and Rey [2006] shows empirically and theoretically that trade reduces volatility, there are other studies including Giovanni and Levchenko [2009], Easterly et al. [2000] with the opposite conclusion. Interestingly, considering multilateral exposure (instead of bilateral exposure which lumps everything apart from the home as foreign) in terms of the network structure reveals a negative relationship. To capture this pattern, I have used a multi-country, multi-sector dynamic model with liquidity constrained households in style of Midrigan and Philippon [2011]. However, since we are using a discrete set of islands as opposed to a continuum of islands assumed in Midrigan and Philippon [2011], the dynamics of liquidity across the economy can be pinned down explicitly and is shown to be intimately related to the structure of the trade network. The demand for liquidity is motivated by a constraint à la Clower [1967] and frictions in price-setting behavior is motivated by imposing a sticky-price structure following Calvo [1983].

On the monetary side, this paper closely follows the cash-in advance literature (Lucas [1980]). In the recent years, the classical quantity theory of money has received a renewed attention, both in theory and practice. The theory of monetary business cycle propounded by Christiano et al. [2005] has been used to study unconventional monetary policies by Gertler and Karadi [2011] and Curdia and Woodford [2010]. Midrigan and Philippon [2011] shows that real activities across regions within U.S.A. are very sensitive to liquidity shocks and not to credit shocks. They also show that the quantitative easing policy has reduced the effects of the recession considerably. The present paper builds on that argument to show that such expansionary monetary policy would have differential impacts on macro variables if the regions have skewed trade connections. Williamson [2008] also studied a similar monetary transmission channel across agents differing in connection to the source of money creation. 


\subsection{Constructing the centrality index}

The export-import statistics is obtained from the Eurostat database (Eurostat [2011]). I construct an $N \times N$ matrix ( $N$ being the number of countries/nodes in the network) denoted by $\overline{\mathcal{T}}$ with elements $\overline{\mathcal{T}}_{i j}$ indicating the how many millions of Euro's worth of goods and services were exported from the $i$-th country to the $j$-th country in a particular year. I fillup the diagonal elements by the respective country sizes (GDP-net export). The matrix thus constructed takes into account both size and the trade relations. Then I normalize the matrix column by column so that each column now sums up to 1 . This step gets rid of the units in which the trades are recorded and also, with this normalization the maximum eigenvalue turns out to be exactly 1 . Thus the eigenvector centrality is unambiguously defined.

\subsection{Centrality and volatility of macro variables}

In Table 5, the variables are trade openness (i.e. (Export+Import)/GDP), domestic credit to GDP ratio (Credit/GDP), total value of stocks traded as a ratio of GDP, log volatility of FDI as a ratio of GDP and log of eigenvector centrality. The volatility have been computed by detrending the respective series (logged) by an HP-filter starting from 1999-2012. Other variables are computed at their 2010 values. Size or GDP being extremely correlated with centrality, does not have substantial explanatory power. We instrument the variable "centrality' which reflects centrality in the trade network, by geographic centrality (see Table 8).

The way I construct the geographic centrality is as follows. From Mayer and Zignago [2011], I get data on bilateral distance capitals of the countries. From that one can construct an $N \times N$ matrix of distance and solve for the dominant eigenvector. Note that this exercise gives the eigenvector centrality of the distance matrix. But one more modification is needed to construct the index of geographic centrality. The country which has the highest score is the most distant from all other countries and conversely, the country with the least score is the least distant from all other countries. Therefore, I define the geographic centrality to be the inverse of the centrality vector of the distance matrix.

The results are shown in Table 7. Another important variable that is negatively related to macro volatility is credit to GDP ratio. Easterly et al. [2000] also makes a similar observation. The first stage F-stat is greater than 10. 


\begin{tabular}{|c|c|c|c|c|c|c|c|c|c|}
\hline Variables & $\sigma_{Y}$ & $\sigma_{C}$ & $\sigma_{I}$ & $\sigma_{Y}$ & $\sigma_{C}$ & $\sigma_{I}$ & $\sigma_{Y}$ & $\sigma_{C}$ & $\sigma_{I}$ \\
\hline constant & $-4.0244^{* * *}$ & $-4.6420^{* * *}$ & $-3.1299^{* * *}$ & 2.1005 & 5.5706 & 4.2603 & $-3.9168^{* * *}$ & $-4.4038^{* * *}$ & $-3.1112^{* * *}$ \\
\hline & $(0.3978)$ & $(0.7236)$ & $(0.3472)$ & $(5.9064)$ & $(10.7903)$ & $(5.0260)$ & $(0.4811)$ & $(0.8733)$ & $(0.4216)$ \\
\hline trade op. & 0.1208 & 0.0274 & 0.1299 & -0.0574 & -0.2699 & -0.0582 & 0.0971 & -0.0251 & 0.1258 \\
\hline & $(0.1602)$ & $(0.2915)$ & $(0.1398)$ & $(0.2345)$ & $(0.4284)$ & $(0.1966)$ & $(1731)$ & $(0.3142)$ & $(0.1517)$ \\
\hline credit/GDP & $-0.3557^{* *}$ & -0.3146 & $-0.3434^{* *}$ & -0.2473 & -0.1339 & -0.2127 & $-0.3477 * *$ & -0.2970 & $-0.3421^{* *}$ \\
\hline & $(0.1605)$ & $(0.2919)$ & $(0.1400)$ & $(0.1911)$ & $(0.3491)$ & $(0.1626)$ & $(1648)$ & $(0.2992)$ & $(0.1444)$ \\
\hline stocks traded/GDP & 0.2741 & 0.1662 & 0.3268 & 0.3175 & 0.2346 & 0.3792 & 0.3040 & 0.2283 & 0.3320 \\
\hline & $(0.3605)$ & $(0.6558)$ & $(0.3146)$ & $(0.3622)$ & $(0.6617)$ & $(0.3082)$ & $(0.3747)$ & $(0.6802)$ & $(0.3284)$ \\
\hline$F D I_{v o l}$ & 0.1624 & -0.0637 & -0.0662 & 0.1599 & -0.0680 & -0.0692 & 0.1634 & -0.0615 & -0.0660 \\
\hline & $(0.1955)$ & $(0.3556)$ & $(0.1706)$ & $(0.1951)$ & $(0.3565)$ & $(0.1660)$ & $(0.1995)$ & $(0.3621)$ & $(0.1748)$ \\
\hline centrality $_{1}$ & $-0.1774^{* * *}$ & $-0.2620^{* *}$ & $-0.2333^{* * *}$ & -0.0130 & 0.0121 & -0.0349 & $-0.1628^{* *}$ & $-0.2298^{*}$ & $-0.2307^{* * *}$ \\
\hline & $(0.0629)$ & $(0.1144)$ & $(0.0549)$ & $(0.1702)$ & $(0.3109)$ & $(0.1448)$ & $(0.0731)$ & $(0.1327)$ & $(0.0641)$ \\
\hline size & & & & -0.2071 & -0.3453 & -0.2499 & & & \\
\hline & & & & $(0.1993)$ & $(0.3640)$ & $(0.1696)$ & & & \\
\hline rel. size & & & & & & & $\begin{array}{l}-0.9316 \\
(2.2361)\end{array}$ & $\begin{array}{l}-2.0621 \\
(4.0591)\end{array}$ & $\begin{array}{l}-0.1616 \\
(1.9596)\end{array}$ \\
\hline$R^{2}$ & 0.4273 & 0.3015 & 0.5850 & 0.4567 & 0.3316 & 0.6257 & 0.4322 & 0.3104 & 0.5852 \\
\hline F-test (p-value) & 0.0288 & 0.1539 & 0.0014 & 0.0382 & 0.1845 & 0.0016 & 0.0543 & 0.2287 & 0.0039 \\
\hline
\end{tabular}

Table 5: $N=27$. Regression results showing log of volatility of macro-variables being negatively related to log of centrality. p-values less than $1 \%, 5 \%$ and $10 \%$ are denoted by $* * *, * *$ and $*$ respectively. Standard errors are shown in parenthesis. 


\begin{tabular}{|c|c|c|c|c|c|c|c|c|c|}
\hline Variables & $\sigma_{Y}$ & $\sigma_{C}$ & $\sigma_{I}$ & $\sigma_{Y}$ & $\sigma_{C}$ & $\sigma_{i}$ & $\sigma_{Y}$ & $\sigma_{C}$ & $\overline{\sigma_{I}}$ \\
\hline \multirow[t]{2}{*}{ constant } & $-3.9372^{* * *}$ & $-4.5026^{* * *}$ & $-3.0464^{* * *}$ & 11.2053 & 21.2926 & $11.9620^{*}$ & $-3.8223^{* * *}$ & $-4.2397^{* * *}$ & $-3.0495^{* * *}$ \\
\hline & $(0.4018)$ & $(0.7256)$ & $(0.3537)$ & $(7.8252)$ & $(14.2786)$ & $(6.7139)$ & $(0.4967)$ & $(0.8948)$ & $(0.4391)$ \\
\hline \multirow[t]{2}{*}{ trade op. } & 0.0502 & 0.0765 & 0.0354 & -0.2195 & -0.5360 & -0.2319 & 0.0321 & -0.1180 & 0.0359 \\
\hline & $(0.1647)$ & $(0.2975)$ & $(0.1450)$ & $(0.2083)$ & $(0.3800)$ & $(0.1787)$ & $(1738)$ & $(0.3131)$ & $(0.1537)$ \\
\hline \multirow[t]{2}{*}{ credit/GDP } & $-0.3146^{*}$ & -0.2513 & $-0.2974^{* *}$ & -0.0934 & 0.1256 & -0.0782 & -0.3073 & -0.2344 & -0.2976 \\
\hline & $(0.1609)$ & $(0.2905)$ & $(0.1416)$ & $(0.1895)$ & $(0.3458)$ & $(0.1626)$ & $(1651)$ & $(0.2975)$ & $(0.1460)$ \\
\hline \multirow[t]{2}{*}{ stocks traded/GDP } & 0.2429 & 0.1056 & 0.3166 & 0.2393 & 0.0996 & 0.3131 & 0.2666 & 0.1599 & 0.3159 \\
\hline & $(0.3765)$ & $(0.6799)$ & $(0.3314)$ & $(0.3540)$ & $(0.6459)$ & $(0.3037)$ & $(0.3885)$ & $(0.6998)$ & $(0.3434)$ \\
\hline \multirow[t]{2}{*}{$F D I_{v o l}$} & 0.1692 & -0.0543 & -0.0556 & 0.1375 & -0.1082 & -0.0870 & 0.1692 & -0.0544 & -0.0556 \\
\hline & $(0.2013)$ & $(0.3635)$ & $(0.1772)$ & $(0.1900)$ & $(0.3466)$ & $(0.1630)$ & $(0.2054)$ & $(0.3700)$ & $(0.1816)$ \\
\hline \multirow[t]{3}{*}{ centrality $_{2}$} & $-0.1615^{* *}$ & $-0.2359^{*}$ & $-0.2203^{* * *}$ & 0.2556 & 0.4746 & 0.1931 & -0.1451 & -0.1983 & -0.2207 \\
\hline & $(0.0640)$ & $(0.1156)$ & $(0.0564)$ & $(0.2236)$ & $(0.4079)$ & $(0.1918)$ & $(0.0766)$ & $(0.1381)$ & $(0.0678)$ \\
\hline & & & & $-0.5125^{* *}$ & $-0.8731^{* *}$ & $-0.5080^{* *}$ & & & \\
\hline \multirow[t]{2}{*}{ rel. size } & & & & & & & -0.9709 & -2.2212 & 0.0266 \\
\hline & & & & & & & $(2.3692)$ & $(4.2680)$ & $(2.0944)$ \\
\hline$R^{2}$ & 0.3941 & 0.2715 & 0.5532 & 0.4898 & 0.3739 & 0.6427 & 0.3992 & 0.2812 & 0.5532 \\
\hline F-test (p-value) & 0.0471 & 0.2132 & 0.0029 & 0.0228 & 0.1151 & 0.0010 & 0.0843 & 0.3005 & 0.0074 \\
\hline
\end{tabular}

Table 6: $N=27$. Regression results showing log of volatility of macro-variables being negatively related to log of centrality. p-values less than $1 \%, 5 \%$ and $10 \%$ are denoted by $* * *, * *$ and $*$ respectively. Standard errors are shown in parenthesis. 


\begin{tabular}{|l|lll|}
\hline Variables & $\sigma_{Y}$ & $\sigma_{C}$ & $\sigma_{I}$ \\
\hline constant & $-4.3141^{* * *}$ & $-4.5960^{* * *}$ & $-3.1551^{* * *}$ \\
trade openness & $(0.4568)$ & $(0.8089)$ & $(0.4545)$ \\
& 0.1380 & 0.0943 & 0.0821 \\
credit/GDP & $(0.1461)$ & $(0.2588)$ & $(0.1454)$ \\
& $-0.4063^{* *}$ & -0.5150 & $-0.3009^{* *}$ \\
stocks traded/GDP & $(0.1662)$ & $(0.2943)$ & $(0.1653)$ \\
& 0.4899 & 0.8568 & 0.4260 \\
$F D I_{\text {vol }}$ & $(0.4184)$ & $(0.7409)$ & $(0.4163)$ \\
& 0.1431 & -0.4681 & -0.1993 \\
centrality & $(0.1789)$ & $(0.3169)$ & $(0.1780)$ \\
& $-0.2391^{* * *}$ & $-0.3480 * *$ & $-0.2670 * * *$ \\
\hline$R^{2}$ & $(0.0909)$ & $(0.1610)$ & $(0.0904)$ \\
\hline Wald $\chi^{2}$-test $\left(\mathrm{p}>\chi^{2}\right)$ & 0.4008 & 0.3211 & 0.4479 \\
\hline
\end{tabular}

Table 7: $N=27$. Regression results showing log of volatility of macro-variables being negatively related to log of centrality. The trade-network centrality has been instrumented by geographic centrality (centrality vector obtained from constructing a network based on actual country-to-country distance along the geodesics).

\subsection{The relationship at quarterly frequency}

For robustness, I have checked the relationship between volatility and centrality with data obtained at quarterly frequency. However, the problem with this data set is that it is not seasonally adjusted. Thus the main analysis is done with annual data. The other drawback is that the source only provides data evaluated at current prices. Thus I have normalized each data point (nominal GDP or consumption or capital formation) by the relevant price index relative to the year 2005. Even though it suffers from such ad-hoc adjustment processes, we see that the negative relationship prevails .

\begin{tabular}{|l|l|}
\hline Variables & Corr. coefficient \\
\hline$C_{\text {trade }}$ and $Y$ & 0.87 \\
$C_{\text {trade }}$ and $C_{\text {geo }}$ & 0.52 \\
$Y$ and $C_{\text {geo }}$ & 0.19 \\
\hline
\end{tabular}

Table 8: Correlation table showing that geographic centrality $C_{g e o}$ is fairly correlated to trade centrality $C_{\text {trade }}$, but much less correlated to the size $Y$. 


\begin{tabular}{|c|c|c|c|c|c|c|c|}
\hline BE & Belgium & EL & Greece & LU & Luxembourg & RO & Romania \\
\hline BG & Bulgaria & ES & Spain & HU & Hungary & SI & Slovenia \\
\hline CZ & Czech Republic & FR & France & MT & Malta & SK & Slovak Republic \\
\hline DK & Denmark & IT & Italy & NL & Netherlands & FI & Finland \\
\hline DE & Germany & CY & Cyprus & AT & Austria & SE & Sweden \\
\hline EE & Estonia & LV & Latvia & PL & Poland & UK & United Kingdom \\
\hline IE & Ireland & LT & Lithuania & PT & Portugal & & \\
\hline
\end{tabular}

Table 9: List of abbreviations of country names.

\subsection{Relative volatility of consumption and capital formation}

\subsection{Data sources}

The export-import data of the countries have been taken from Eurostat [2011]. Two sets of data are provided there: on dispatches and arrivals. Arrivals, i.e. imports from other EU countries, are particularly under-estimated due to misreporting of the corresponding countries. Hence, there are discrepancies between the data. Officially, Eurostat considers dispatches to be the most reliable gauge of Intra-EU trade and we also follow the same rule. Data on GDP, consumption and gross capital formation in the Euro-countries have been downloaded from Eurostat database (both yearly and quarterly). Data on money supply, total stocks traded, credit to private sector and FDI are obtained from the World Bank database.

\subsection{Simulating the model}

The steps for solving the model is listed below.

1. Solve for the consumers' static problem of the $i$-th island of allocating money between consumption of tradables and non-tradables (Sec. 8.8.1). Using the assumption of market clearance for all tradable goods, one can solve for the money demand and hence the linkages (Sec. 8.8.3).

2. Thus one gets the liquidity flow equation $A(t+1)=\mathcal{T} A(t)$ (see Eqn. 42). Calibrate $\mathcal{T}$ to the actual trade flow matrix.

3. Start with an arbitrary vector of liquidity holding $A(0)$. Simulate the liquidity flow sufficiently long to get convergence of asset holding. Call the equilibrium asset-holding $A^{*}$ where $A^{*}=\mathcal{T} A^{*}$. 
4. Solve for the consumers' dynamic problem of the $i$-th island of consumption-savings decision (Sec. 8.8.1). Solve for the producers' problem in the $i$-th island (Sec. 8.8.4).

5. Construct the list of equations describing the $i$-th economy and log-linearize it around the steady state (Sec. 8.8.5, 8.8.6, 8.8.7). Thus one gets a system of equations that describes the fluctuation of the real variables following liquidity growth shocks.

6. Simulate the liquidity flow equation starting from the steady state $A^{*}$ with liquidity injection to all islands commensurate with the size of the smallest island. This assumption ensures that all shocks are relatively small so that all approximations (e.g. the loglinearization) makes sense. The shocks across island follow the same AR(1) process and are independent. The aggregate liquidity flow is given by $A(t+1)=\mathcal{T}\left(A(t)+A^{\text {exo }}(t)\right)$. Store the time-series of evolution of liquidity-holding for each island.

7. Estimate an AR(1) process for liquidity evolution for each island. Even though the exogenous shocks are i.i.d., due to the linkages (captured by the transition matrix $\mathcal{T}$ ) the estimated coefficients and the volatility would be different. Given the sequence of liquidity holding of an island $\left\{a_{i}(t)\right\}_{t=1, \ldots, T}$, we can rewrite the flow equation for $i$-th island as

$$
a_{i}(t+1)=g_{i}(t) a_{i}(t)
$$

Thus we generate a sequence of growth rate of assets $\left\{g_{i}(t)\right\}_{t=1, \ldots, T}$. By regressing $\log g_{i}(t)$ on $\log g_{i}(t-1)$, we get the estimate of the coefficient $\left(\bar{\pi}_{i}\right)$ and thus, we can construct a proxy series of the growth rate shock as

$$
\log g_{i}(t)=\bar{\pi}_{i} \log g_{i}(t)+\epsilon_{i}^{g}
$$

8. Feed it into a linearized system of equations describing the real variables of each islands (Sec. 8.8.8) to generate time-series of real variables in each island. In actual simulation, both the liquidity shock and an i.i.d. TFP shock is given to all islands.

9. I treat the model as generating data at quarterly frequencies (the friction parameters have been calibrated at the same; see Table. 4). Thus I aggregate sets of four consecutive data points in the synthetic series to generate a new series at yearly frequency. All statistics have been calculated using this series. 


\subsection{Mathematical derivations}

\subsubsection{Consumers' maximization problem}

We set-up the Lagrangian as the following:

$$
\begin{gathered}
L=\sum_{t=0}^{\infty} \beta^{t} E\left(\alpha_{i} \log \left(C_{i}^{F}\right)+\left(1-\alpha_{i}\right) \log \left(C_{i}\right)-\bar{B}_{i} L_{i}\right. \\
+\quad \lambda_{1 t}\left(a_{i}(t-1)+P_{i}^{F} Y_{i t}^{F}+\Delta a_{i}^{e x o}(t)-P_{i} C_{i}-\sum_{j}^{N} P_{j}^{F} C_{i j}^{F}\right) \\
\left.+\quad \lambda_{2 t}\left(w_{i} L_{i}(t)+r_{i} K_{i}(t)+(1-\delta) K_{i}(t)+\xi_{i}(t)-K_{i}(t+1)-\frac{a_{i}(t)}{P_{i}(t)}\right)\right) .
\end{gathered}
$$

We make a simplifying assumption that $\bar{B}_{i}=\left(1-\alpha_{i}\right) B$. The choice variables are (for the $i$-th country) $C_{i j}^{F}(t), C_{i}(t), L_{i}(t), K_{i}(t+1)$ and $a_{i}(t)$.

$$
\begin{aligned}
\frac{\alpha_{i} \beta_{i j}}{C_{i j}^{F}(t)} & =\lambda_{1 t} P_{j}^{F}(t) \\
\frac{1-\alpha_{i}}{C_{i}(t)} & =\lambda_{1 t} P_{i}(t), \\
B\left(1-\alpha_{i}\right) & =-\lambda_{2 t} w_{i}(t), \\
\lambda_{2 t} & =\beta E\left(\lambda_{2(t+1)}\left(r_{i}(t+1)+(1-\delta)\right)\right) \\
\frac{\lambda_{2 t}}{P_{i}(t)} & =\beta E\left(\lambda_{1(t+1)}\right) .
\end{aligned}
$$

By combining the first order conditions, the following equations are derived.

$$
\begin{aligned}
\frac{1}{w_{i}(t)} & =\beta E\left(\frac{1}{w_{i}(t+1)}\left(r_{i}(t+1)+(1-\delta)\right)\right. \\
-\frac{B}{w_{i}(t) P_{i}(t)} & =\beta\left(1-\alpha_{i}\right) E\left(\frac{1}{P_{i}(t+1) C_{i}(t+1)}\right)
\end{aligned}
$$

\subsubsection{International market clearance}

So far, we have solved the agent's problem assuming that the international prices are exogenous. To solve for $P_{j}^{F}(t)$, we consider all islands together. From the first order conditions and the budget equation, we know that total expenditure on the $j$-th foreign good

$$
P_{j}^{F}(t) C_{i j}^{F}(t)=\alpha_{i} \beta_{i j}\left(P_{i}^{F}(t) Y_{i}^{F}(t)+a_{i}(t-1)\right)
$$


where the $Y_{i}^{F}(t)$ is a stochastic endowment for all islands $i \leq N$. Thus, market-clearing requires

$$
\begin{aligned}
Y_{j}^{F}(t) & =\sum_{i=1}^{N} C_{i j}^{F}(t) \\
& =\sum_{i=1}^{N} \frac{\alpha_{i} \beta_{i j}\left(P_{i}^{F}(t) Y_{i}^{F}(t)+a_{i}(t-1)\right)}{P_{j}^{F}(t)}
\end{aligned}
$$

\subsubsection{Derivation of the asset flow equations}

First, the solution of the model without exogenous liquidity shocks is shown. In the next step, we add that shock. Let us denote the nominal value of tradables, $P_{j}^{F}(t) Y_{j}(t)$ by $x_{j}(t)$. In vector notation, $X(t)=\left\{x_{1}(t), x_{2}(t), \ldots, x_{N}(t)\right\}^{T}$ and $A(t-1)=\left\{a_{1}(t-1), a_{2}(t-\right.$ $\left.1), \ldots, a_{N}(t-1)\right\}^{T}$ with $v^{T}$ denoting the transpose of vector $v$. Therefore,

$$
X(t)=Q X(t)+Q A(t-1)
$$

where

$$
Q=\left[\begin{array}{cccc}
\alpha_{1} \beta_{11} & \alpha_{2} \beta_{21} & \ldots & \alpha_{N} \beta_{N 1} \\
\alpha_{1} \beta_{12} & \alpha_{2} \beta_{22} & \ldots & \alpha_{N} \beta_{N 2} \\
\cdot & \cdot & \ldots & \cdot \\
\cdot & \cdot & \ldots & . \\
\alpha_{1} \beta_{1 N} & \alpha_{2} \beta_{2 N} & \ldots & \alpha_{N} \beta_{N N}
\end{array}\right]
$$

Thus, the solution is

$$
X(t)=(I-Q)^{-1} Q A(t-1) .
$$

Recall that the demand for asset is given as

$$
a_{i}(t)=\left(1-\alpha_{i}\right)\left(a_{i}(t-1)+P_{i}^{F}(t) Y_{i}^{F}(t)\right) .
$$

By substituting the solution, we get

$$
\begin{aligned}
A(t) & =D_{1-\alpha} A(t-1)+D_{1-\alpha} X(t) \\
& =D_{1-\alpha} A_{t-1}+D_{1-\alpha}(I-Q)^{-1} Q A(t-1) \\
& =\left(D_{1-\alpha}+D_{1-\alpha}(I-Q)^{-1} Q\right) A(t-1) \\
& =\mathcal{T} A(t-1),
\end{aligned}
$$


where $\mathcal{T}=\left(D_{1-\alpha}+D_{1-\alpha}(I-Q)^{-1} Q\right)$ is the transition matrix. We define $D_{1-\alpha}$ as a diagonal matrix with elements of the vector $1-\alpha=\left\{1-\alpha_{1}, 1-\alpha_{2}, \ldots, 1-\alpha_{N}\right\}$ along the diagonal.

By forwarding one-period, we get

$$
A(t+1)=\mathcal{T} A(t)
$$

If we include the exogenous liquidity shocks, the process can be rewritten as

$$
A(t+1)=\mathcal{T}\left(A(t)+A^{\text {exo }}(t)\right) .
$$

\subsubsection{Producers' problem in the $i$-th island}

Following the structure assumed in the model, there is no linkage in the production processes across islands. Thus all production decisions are taken separately. In the following, all variables are specific to one island (generically indexed by $i$ ) and specific to the production process of non-tradables (indexed by $D$ ). To simplify the exposition, I do not use the superscript $D$ and subscript $i$.

Final goods production Recall that the bundling technology is given by

$$
Y_{t}=\left[\int_{0}^{1} Y_{t}(k)^{\frac{\psi-1}{\psi}} d k\right]^{\frac{\psi}{\psi-1}}
$$

with $\psi>1$. A profit maximizing firm maximizes

$$
\pi_{t}=P_{t} Y_{t}-\int_{0}^{1} P_{t}(k) Y_{t}(k) d k,
$$

subject to the above bundling technology. Therefore, the problem is to maximize

$$
P_{t}\left[\int_{0}^{1} Y_{t}(k)^{\frac{\psi-1}{\psi}} d k\right]^{\frac{\psi}{\psi-1}}-\int_{0}^{1} P_{t}(k) Y_{t}(k) d k,
$$

and the first order condition is clearly,

$$
P_{t}\left[\int Y_{t}(k)^{\frac{\psi-1}{\psi}} d k\right]^{\frac{1}{\psi-1}} Y_{t}(k)^{-1} \psi=P_{t}(k) .
$$

This equation can be simplified to write down the demand function for good $k$ as

$$
Y_{t}(k)=Y_{t}\left(\frac{P_{t}}{P_{t}(k)}\right)^{\psi} .
$$


By plugging it back into the bundling technology, we get

$$
Y_{t}=Y_{t}\left[\int_{0}^{1}\left(\frac{P_{t}}{P_{t}(k)}\right)^{\psi-1} d k\right]^{\frac{\psi}{\psi-1}}
$$

This gives us the expression for the price index $P_{t}$ :

$$
P_{t}=\left[\int_{0}^{1} P_{t}(k)^{1-\psi} d k\right]^{\frac{1}{1-\psi}} .
$$

Intermediate goods The intermediate goods firms resets price to maximize the market value of the firm subject to the demand for their output by the final goods firms conditional on the fact that there is a constant probability $(1-\rho$, following a Calvo rule) of getting the chance to reset prices every period in future. The rest of the firms continue with the old price. The production function is given by

$$
Y_{t}(k)=\lambda_{t} K_{t}^{\theta} H_{t}^{1-\theta}(k),
$$

$\lambda_{t}$ being a common technology shock to all firms. Markets for capital and labor are competitive. Hence, their prices are taken to be constant by the firms. The problem of the firm producing $k$-th variety is

$$
E_{t} \sum_{i=0}^{\infty} \beta^{i} \rho^{i}\left[P_{t}^{*}(k) Y_{t+i}\left(\frac{P_{t+i}}{P_{t} *(k)}\right)^{\psi}-P_{t+i} r_{t+i} K_{t+i}(k)-P_{t+i} w_{t+i} H_{t+i}(k)\right]
$$

subject to the production technology and the demand function,

$$
Y_{t+i}\left(\frac{P_{t+i}}{P_{t}^{*}(k)}\right)^{\psi}=\lambda_{t} K_{t}^{\theta} H_{t}^{1-\theta}(k)
$$

Solving the problem, we get the reset price as

$$
P_{t}^{*}(k)=\frac{\psi}{\psi-1} \frac{E_{t} \sum_{i=0}^{\infty}(\beta \rho)^{i} P_{t+i} Y_{t+i}(k) \frac{w_{t+i}}{(1-\theta) \lambda_{t+i}}\left[\frac{r_{t+i}(1-\theta)}{w_{t+i} \theta}\right]}{E+t \sum_{i=0}^{\infty}(\beta \rho)^{i} Y_{t+i}(k)} .
$$

Notice that all firms that are reseting the prices, will choose the same new price. Hence, from the equation of the price index, we get

$$
P_{t}^{1-\psi}=\rho P_{t-1}^{1-\psi}+(1-\rho)\left(P_{t}^{*}\right)^{1-\psi}
$$




\subsubsection{The aggregate model}

Note that due to the unit elasticity of the tradabls and non-tradables in the utility function, the demand functions are completely separable. Below we list the full system of equations for the non-tradable sector $(D)$ of the $i$-th economy:

$$
\begin{aligned}
\frac{1}{\beta} & =E\left[\frac{w_{i}(t)}{w_{i}(t+1)}\left(r_{i}(t+1)+1-\delta\right)\right] \\
\frac{B}{w_{i}(t) P_{i}(t)} & =E\left(\frac{\alpha \beta}{P_{i}(t+1) C_{i}(t+1)}\right) \\
P_{i}(t) C_{i}(t) & =g_{i}(t) a_{i}(t-1) \\
K_{i}(t+1)+\frac{a_{i}(t)}{P_{i}(t)} & =Y_{i}(t)+(1-\delta) K_{i}(t) \\
P_{k}^{D *}(t) & =\frac{\psi}{\psi-1} \frac{E_{t}\left(\sum_{i=0}^{\infty}(\beta \rho)^{i} P_{t+i} Y_{t+i}(k) \frac{w_{t+i}}{(1-\theta) \lambda_{t+i}}\left[\frac{r_{t+i}(1-\theta)}{w_{t+i} \theta}\right]\right)}{E_{t}\left(\sum_{i=0}^{\infty}(\beta \rho)^{i} Y_{t+i}(k)\right)} \\
\left(P_{i}\right)^{1-\psi} & =\rho\left(P_{i}\right)^{1-\psi}(t-1)+(1-\rho)\left(P_{i}^{*}(t)\right)^{1-\psi} \\
a_{i}(t) & =g_{i}(t) a_{i}(t-1)
\end{aligned}
$$

Note that it is the third and the last equation (regarding money growth, $g_{i}(t)$ ) is what connects the domestic economy of the $i$-th island to the international market. Any trade with foreign countries potentially induce a fluctuation in the growth rate $g_{i}(t)$ of assets which in turn affects the domestic economy through the cash-in advance constraint. 


\subsubsection{Steady state}

We describe the steady state of the $i$-th island by the following set of equations. For simplifying exposition, we do not attach subscript $i$ to all variables below.

$$
\begin{aligned}
\bar{\beta} & =\bar{r}+1-\delta \\
\beta \bar{w} & =-B \bar{C} \\
\bar{C} & =\frac{\bar{a}}{\bar{P}} \\
\bar{a} & =\bar{w} \bar{H}+\bar{\xi}+(\bar{r}-\delta) \bar{K} \\
\bar{P} & =\bar{Y}-\delta \bar{K} \\
\bar{P} & =\bar{P}(k), \\
\bar{Y}(k) & =\bar{Y}, \\
\bar{w} & =\left[\frac{(\psi-1)(1-\theta)^{1-\theta} \theta^{\theta}}{\psi \bar{r}^{-1}}\right. \\
\bar{H} & =\left[\frac{\bar{r}(1-\theta)}{\bar{w} \theta}\right]^{\theta} \bar{Y}, \\
\bar{K} & =\left[\frac{\bar{r}(1-\theta)}{\bar{w} \theta}\right]^{\theta-1} \bar{Y}, \\
\bar{Y} & =\frac{\bar{\psi}}{B\left(\bar{w}\left[\frac{\bar{r}(1-\theta)}{\bar{w} \theta}\right]^{\theta}+\frac{1}{\psi}+(\bar{r}-\delta)\left[\frac{\bar{r}(1-\theta)}{\bar{w} \theta}\right]^{\theta-1}\right)} \\
\bar{\xi} & =\frac{\bar{Y}}{\psi} \cdot
\end{aligned}
$$

Any variable of the form $\bar{x}$ denotes the steady state value of the variable $x$. 


\subsubsection{Log-linearized version}

I log-linearize the system of equations described in Sec. 8.8.5 following Uhlig's mothod. The log-linearized version of the above system of equation is

$$
\begin{aligned}
0= & \tilde{w}_{t}+\beta \bar{r} E_{t} \tilde{r}_{t+1}-E_{t} \tilde{w}_{t+1}, \\
0= & \tilde{a}_{t}-\tilde{a}_{t-1}-\tilde{g}_{t}, \\
0= & \beta E_{t} \tilde{P}_{t+1}+\frac{(1-\theta)(1-\rho)(1-\beta \rho)}{\rho} \tilde{w}_{t}-\frac{(1-\rho)(1-\beta \rho)}{\rho} \tilde{\lambda}_{t} \\
& \quad+\frac{\theta(1-\rho)(1-\beta \rho)}{\rho} \tilde{r}_{t}-(1+\beta) \tilde{P}_{t}+\tilde{P}_{t-1}, \\
0= & \tilde{g}_{t}+\tilde{a}_{t-1}-\tilde{P}_{t}-\tilde{C}_{t}, \\
0= & \bar{Y} \tilde{Y}_{t}+(1-\delta) \bar{K} \tilde{K}_{t}-\bar{K} \tilde{K}_{t+1}-\frac{\bar{a}}{\bar{P}} \tilde{a}_{t}+\frac{\bar{a}}{\bar{P}} \tilde{P}_{t}, \\
0= & \tilde{w}_{t}+\tilde{P}_{t}-\tilde{a}_{t}-\pi \tilde{g}_{t}, \\
0= & \tilde{\lambda}_{t}+(1-\theta) \tilde{H}_{t}+\theta \tilde{K}_{t}-\tilde{Y}_{t}, \\
0= & \tilde{H}_{t}+\tilde{w}_{t}-\tilde{K}_{t}-\tilde{r}_{t} .
\end{aligned}
$$

Any variable of the form $\tilde{x}$ denotes the $\log$ deviation from the steady state value of the variable $x$ i.e. $\tilde{x}=\log x-\log \bar{x}$.

\subsubsection{Dynamics of the linearized system around the steady state}

In solving this model, I explicitly follow the exposition of McCandless [2008]. A more detailed description of the methods followed here will be available in the same reference (see also Uhlig $[1999])$. Let $\chi_{t}=\left[\tilde{K}_{t+1}, \tilde{a}_{t}, \tilde{P}_{t}\right]^{\prime}, \omega_{t}=\left[\tilde{r}_{t}, \tilde{w}_{t}, \tilde{C}_{t}, \tilde{Y}_{t}, \tilde{H}_{t}\right]^{\prime}$ and $\eta_{t}=\left[\tilde{\lambda}_{t}, \tilde{g}_{t}\right]^{\prime}$. Then the system of eqn can be rewritten as

$$
\begin{aligned}
0 & =M_{1} \chi_{t}+M_{2} \chi_{t-1}+M_{3} \omega_{t}+M_{4} \eta_{t}, \\
0 & =E_{t}\left[M_{5} \chi_{t+1}+M_{6} \chi_{t}+M_{7} \chi_{t-1}+M_{8} \omega_{t+1}+M_{9} \omega_{t}+M_{10} \eta_{t+1}+M_{11} \eta_{t}\right], \\
\eta_{t+1} & =M_{12} \eta_{t}+\epsilon_{t},
\end{aligned}
$$

with suitable numerical values for the matrices $M_{1, \ldots, 12}$. The solution of the above system is given by

$$
\begin{aligned}
\chi_{t+1} & =A \chi_{t}+B \eta_{t}, \\
\omega_{t} & =C \chi_{t}+D \eta_{t},
\end{aligned}
$$


where the matrices $A, B, C, D$ are functions of matrices $M_{1, \ldots, 12}$. More specifically, the matrices $A, B, C, D$ can be found in the follwoing way: $A$ solves the matrix quadratic equation:

$$
\left(M_{5}-M_{8} M_{3}^{-1} M_{1}\right) A^{2}-\left(M_{8} M_{3}^{-1} M_{2}-M_{6}+M_{9} M_{3}^{-1} M_{1}\right) A-M_{9} M_{3}^{-1} M_{2}+M_{7}=0 .
$$

In the next step, we calculate

$$
C=-M_{3}^{-1}\left(M_{1} A+M_{2}\right)
$$

Matrix $B$ solves

$$
\begin{aligned}
\operatorname{vec}(B)=\left(M_{12}^{\prime} \otimes\left(M_{5}-M_{8} M_{3}^{-1} M_{1}\right)\right. & \left.+I_{k} \otimes\left(M_{5} A+M_{6}+M_{8} C-M_{9} M_{3}^{-1} M_{1}\right)\right)^{-1} \\
& \times \operatorname{vec}\left(\left(M_{8} M_{3}^{-1} M_{4}\right) M_{12}+M_{9} M_{3}^{-1} M_{4}-M_{11}\right),
\end{aligned}
$$

and finally,

$$
D=M_{3}^{-1}\left(M_{1} B+M_{4}\right)
$$

\subsection{Random network (E-R) vs. scale-free network}

In a linear network, we can exactly pin down how the shock propagates from one island to another since there is exactly one path through which the shock can spread. However, in a more general context that would not be possible because the number of paths through which any two given islands can be connected, is possibly more than one. Therefore, for any given graph with a particular degree distribution, we need some other metric to understand the speed of propagation. The diameter of a graph is the maximal distance between any pair of nodes i.e. it is the longest shortest path. For a random graph (Erdos-Renyi) with number of nodes $N$ and average degree $k>\log (N)$, the diameter is approximately $\log (N) / \log (k)$ (Jackson [2010]). Thus the expected diameter of a random graph is $O(\log N)$. Similar property is shown by networks with small world properties (see Dorogovtsev and Mendes [2003]). On the other hand, the diameter in a scale-free network, having $N$ nodes and degree distribution $p(d) \sim d^{-a}$, with the exponent $2<a<3$ have a much smaller diameter, is proportional to $\log \log N$ (Cohen and Havlin [2003]). For $a>3$, the diameter behaves as $O(\log N)$. As is evident from the form of the degree distribution, a scale-free network is characterized by existence of 'hubs' i.e. nodes which connects with a huge number of other

nodes and thus have a disproportionate representation in the degree distribution. Because of these hubs, the average distance of the network decreases considerably. For a complete review of different network structures, see Albert and Barabasi [2002]. 


\subsection{Cover times for two regular networks}

If we have a linear network (chain of islands),

$$
c_{j}=4 N^{2}
$$

On the other hand, for a complete network (with self-loops)

$$
c_{j}=N \log N
$$

\section{References}

Acemoglu, D., Carvalho, V., Ozdaglar, A., and Tahbaz-Salehi, A. (2012). The network origin of economic fluctuations. Econometrica, 80:1977-2016.

Albert, R. and Barabasi, A.-L. (2002). Statistical mechanics of complex networks. Review of Modern Physics, 74:47-97.

Armington, P. S. (1969). A theory of demand for products distinguished by place of production. IMF Staff Papers, 16:159-78.

Barlevy, G. (2004). The costs of business cycles under endogenous growth. American Economic Review, 96:964.

Bech, M., Chapman, J., and Garrat, R. (2010). Which bank is the "central" bank? Journal of monetary economics, 57:352-363.

Bejan, M. (2006). Trade openness and output volatility.

Bigio, S. and Lao, J. (2013). Financial frictions in production networks.

Bruneau, L., Joye, A., and Merkli, M. (2010). Infinite products of random matrices and repeated interaction dynamics. Annales de lInstitut Henri Poincare - Probabilites et Statistiques, 46:442.

Burgess, R. and Donaldson, D. (2012). Railroads and the demise of famine in colonial india.

Calvo, G. (1983). Staggered pricing in a utility-maximizing framework. Journal of Monetary Economics, 12:383-98.

Caselli, F., Koren, M., Lisicky, M., and Tenreyro, S. (2014). Diversification through trade. 
Cavallo, E. and Frankel, J. (2008). Does openness to trade make countries more vulnerable to sudden stops, or less? using gravity to establish causality. Journal of International Money and Finance, 27:1430.

Chaney, T. (2014). The network structure of international trade. American Economic Review, (forthcoming).

Choudum, S. A. (1986). A simple proof of the erdos-gallai theorem on graph sequences. Bulletin of the Australian Mathematical Society, 33(1):67-70.

Christiano, L., Eichenbaum, M., and Evans, C. (2005). Nominal rigidities and the dynamic effects of a shock to monetary policy. Jounal of Political Economy, 113:1.

Clower, R. W. (1967). A reconsideration of the microfoundations of monetary theory. Western Economic Journal, 6(1):1-8.

Cohen, R. and Havlin, S. (2003). Scale-free networks are ultrasmall. Physical Review Letters, 90:058701.

Curdia, V. and Woodford, M. (2010). Conventional and unconventional monetary policy. Federal Reserve Bank of St. Louis Review, 92:229.

Dorogovtsev, S. N. and Mendes, J. F. F. (2003). Evolution of Networks: From Bilogical Nets to the Internet and $W W W$. Oxford University Press.

Dumas, B. (1992). Dynamic equilibrium and the real exchange rate in a spatially separated world. Review of Financial Studies, 5(2):153-80.

Dupor, W. (1999). Aggregation and irrelevance in multi-sector models. Journal of Monetary Economics, 43:391.

Easterly, W. R., Islam, R., and Stiglitz, J. (2000). Shaken and stirred: Explaining growth volatility. Macroeconomic paradigms for less developed countries.

Eurostat (2011). External and intra-EU trade A statistical yearbook Data 1958 - 2010.

Farshbaf, A. (2012). Does geographical diversification in international trade reduce business cycle volatility?

Gabaix, X. (2011). Granular origin of aggregate fluctuations. Econometrica, 79-3.

Gertler, M. and Karadi, P. (2011). A model of unconventional monetary policy. Journal of Monetary Economics, 58:17. 
Ghiglino, C. and Goyal, S. (2010). Keeping up with the neighbors: Social interaction in a market economy. Journal of the European Economic Association, 8(1):90119.

Giovanni, J. D. and Levchenko, A. (2009). Trade openness and volatility. Review of Economics and Statistics, 91:558.

Giovanni, J. D. and Levchenko, A. A. (2012). Country size, international trade, and aggregate fluctuations in granular economies. Journal of Political Economy, 120:1083.

Goyal, S. (2009). Connections. Princeton University Press.

Gray, J. and Potter, P. B. K. (2012). Trade and volatility at the core and periphery of the global economy. International Studies Quarterly, 56:793.

Haddad, M., Lim, J. J., Pancaro, C., and Saborowski, C. (2012). Trade openness reduces growth volatility when countries are well diversified. ECB working paper series.

Horvath, M. (1998). Cyclicality and sectoral linkages: Aggregate fluctuations from sectoral shocks. Review of Economic Dynamics, 1:781.

Jackson, M. (2010). Social and Economic Networks. Princeton University Press.

Jackson, M., Elliott, M., and Golub, B. (2014). Financial networks and contagion. American Economic Review, 104(10):3115-53.

Kelly, B., Lustig, H., and Nieuwerburgh, S. V. (2013). Firm volatility in granular networks.

Koren, M. and Tenreyro, S. (2007). Volatility and development. Quarterly Journal of Economics, 122(1):243-283.

Kose, M. A., Prasad, E. S., and Terrones, M. E. (2003). How does globalization affect the synchronization of business cycles? American Economic Review: Papers and Proceedings.

La'o, J. (2014). A traffic jam theory of recessions.

Lucas, R. E. (1980). Models of Monetary Economics, chapter Equilibrium in a Pure Currency Economy. Federal Reserve Bank of Mineapolis.

Martin, P. and Rey, H. (2006). Globalization and emerging markets: With or without crash? American Economic Review, 96:1631.

Mayer, T. and Zignago, S. (2011). Notes on cepiis distances measures: The geodist database. McCandless, G. (2008). The ABCs of RBCs. Harvard University Press. 
Midrigan, V. and Philippon, T. (2011). Household leverage and the recession.

Oberfield, E. (2013). Business networks, production chains, and productivity: A theory of input-output architecture.

Prasad, E. S., Rogoff, K., Wei, S., and Kose, M. A. (2007). Financial globalization, growth, and volatility in developing countries. In Harrison, A., editor, Globalization and Poverty. University of Chicago Press.

Ramey, G. and Ramey, V. A. (1995). Cross-country evidence on the link between volatility and growth. American Economic Review, 85:1138.

Simon, C. and Blume, L. (2007). Mathematics for economics. Norton.

Uhlig, H. (1999). A toolkit for analysing nonlinear dynamic stochasic models easily. In Marimon, R. and Scott, A., editors, Computational methods for the study of dynamic economies. Oxford University Press.

Vega-Redondo, F. (2007). Complex Social Networks. Cambridge University Press.

Williamson, S. D. (2008). Monetary policy and distribution. Journal of Monetary Economics, 55:1038. 